\title{
How Dietary Intake Has Been Assessed In African Countries?
}

A Systematic Review

\section{Vila-Real, Catarina}

2018

Vila-Real , C , Pimenta-Martins , A, Gomes , A M , Pinto , E \& Maina , H N 2018 , ' How Dietary Intake Has Been Assessed In African Countries? A Systematic Review ' , Critical

Reviews in Food Science and Nutrition , vol. 58 , no. 6 , pp. 1002-1022 . https://doi.org/10.1080/10408398.2016.123

http://hdl.handle.net/10138/326560

https://doi.org/10.1080/10408398.2016.1236778

unspecified

acceptedVersion

Downloaded from Helda, University of Helsinki institutional repository.

This is an electronic reprint of the original article.

This reprint may differ from the original in pagination and typographic detail.

Please cite the original version. 


\section{Critical Reviews in Food Science and Nutrition}

\section{How dietary intake has been assessed in African countries? A systematic review}

\section{Catarina Vila-Real , Ana Pimenta-Martins, Ana Maria Gomes, Elisabete Pinto \& Ndegwa Henry Maina}

To cite this article: Catarina Vila-Real , Ana Pimenta-Martins, Ana Maria Gomes, Elisabete Pinto \& Ndegwa Henry Maina (2016): How dietary intake has been assessed in African countries? A systematic review, Critical Reviews in Food Science and Nutrition, DOI: 10.1080/10408398.2016.1236778

To link to this article: http://dx.doi.org/10.1080/10408398.2016.1236778

Accepted author version posted online: 20

Dec 2016.

Published online: 20 Dec 2016.

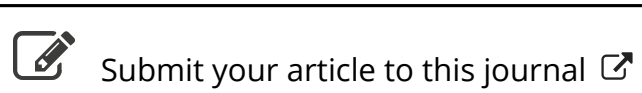

Џll Article views: 39

Q View related articles ¿ك

View Crossmark data ־ 


\title{
How dietary intake has been assessed in African countries? A systematic review
}

\author{
Catarina Vila-Real (D) ${ }^{\mathrm{a}}$, Ana Pimenta-Martins ${ }^{\mathrm{a}}$, Ana Maria Gomes ${ }^{\mathrm{a}}$, Elisabete Pinto ${ }^{\mathrm{a}, \mathrm{b}}$, and Ndegwa Henry Maina ${ }^{\mathrm{c}}$ \\ a Universidade Católica Portuguesa, CBQF - Centro de Biotecnologia e Química Fina - Laboratório Associado, Escola Superior de Biotecnologia, Rua

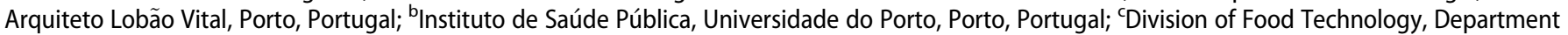 \\ of Food and Environmental Sciences, University of Helsinki, Helsinki, Finland
}

\begin{abstract}
Background: Dietary patterns are often considered as one of the main causes of non-communicable diseases worldwide. It is of utmost importance to study dietary habits in developing countries since this work is scarce.

Objective: To summarize the most recent research conducted in this field in African countries, namely the most used methodologies and tools.

Methods: A systematic review was conducted on MEDLINE $^{\circledR} /$ PubMed, aiming to identify scientific publications focused on studies of dietary intake of different African populations, in a ten-year period. Papers not written in English/Portuguese/Spanish, studies developed among African people but not developed in African countries, studies aiming to assess a particular nutrient/specific food/food toxin and studies that assessed dietary intake among children were excluded.

Findings: Out of 99 included studies, the 24-hour recall and the food-frequency questionnaire were the most used dietary intake assessment tools, used to assess diet at an individual level. It was also observed that often country-unspecific food composition databases are used, and the methodologies employed are poorly validated and standardized.

Conclusions: There is an emergent need to improve the existing food databases by updating food data and to develop suitable country-specific databases for those that do not have their own food composition table.
\end{abstract}

\section{KEYWORDS}

Dietary intake assessment tools; 24-hour recall; Foodfrequency questionnaire; food composition databases; African countries

\section{Introduction}

Over the last years, we have witnessed a shift in demographics in developing countries, namely in what concerns the lifetime expectancy and the organization of the societies, since there has been a growth in urbanization. This reality has led to changes in people's lifestyles, resulting in a transition from traditional to modern realities, subsequently leading to an epidemiological transition. Developing countries, especially in Africa have shown an increase in the prevalence of Non-Communicable Diseases (NCDs), while Communicable Diseases are still a major challenge, despite the success of vaccination programs (Boutayeb, 2006; World Health Organization - Reginal Office for Africa, 2006; Haregu et al., 2014; Islam et al., 2014). According to the World Health Organization (WHO) Global Status Report (2011), NCDs are responsible for almost $80 \%$ of deaths in low and middle-income countries. Although the major cause of deaths in African countries are communicable, maternal, perinatal, and nutritional diseases, NCDs are emerging in an exponential rate, being foreseen a switch of trends a switch of trends in 2030 (World Health Organization, 2011).

Dietary patterns are often considered as one of the main causes of NCDs, so it is of utmost importance to describe the expectable nutritional transition, in order to quantify the impact of diet in this group of diseases. However, in developing countries this work is scarce or insufficiently documented, probably due to logistic and financial constraints. According to Pisa et al. (2014), another reason that justifies the scarcity of this work is the lack of reliable dietary assessment methodologies, which upholds the emergent need for the development, validation and standardization of tools for measuring and monitoring food intake in different countries (Pisa et al., 2014). In this regard some work has been done, namely by the Dietary Exposure (DEX) assessment group (Pisa et al., 2014), which addresses its research to studies on diet and cancer and other NCDs. Its main goal is to develop and to validate dietary methods to assess dietary exposures.

The assessment of dietary intake is imperative to know population's food habits, including the inadequacy prevalence of different nutrients, as well as the study of the relationships between dietary patterns and disease. Dietary assessment may be done at national, household and individual level, when approaching food supply and production, food purchases or food consumption, respectively (Thompson and Byers, 1994; Gibson, 2005). At the individual level, several methodologies may be used, and these may be divided into two major groups: retrospective and prospective methods. Retrospective methods comprise the twenty-four hour Recall (24hR), the Food-Frequency Questionnaire (FFQ), and the Dietary History (DH), while prospective methods include Food/Weighed Records (WR) (Thompson and Byers, 1994; Gibson, 2005). Ideally these 


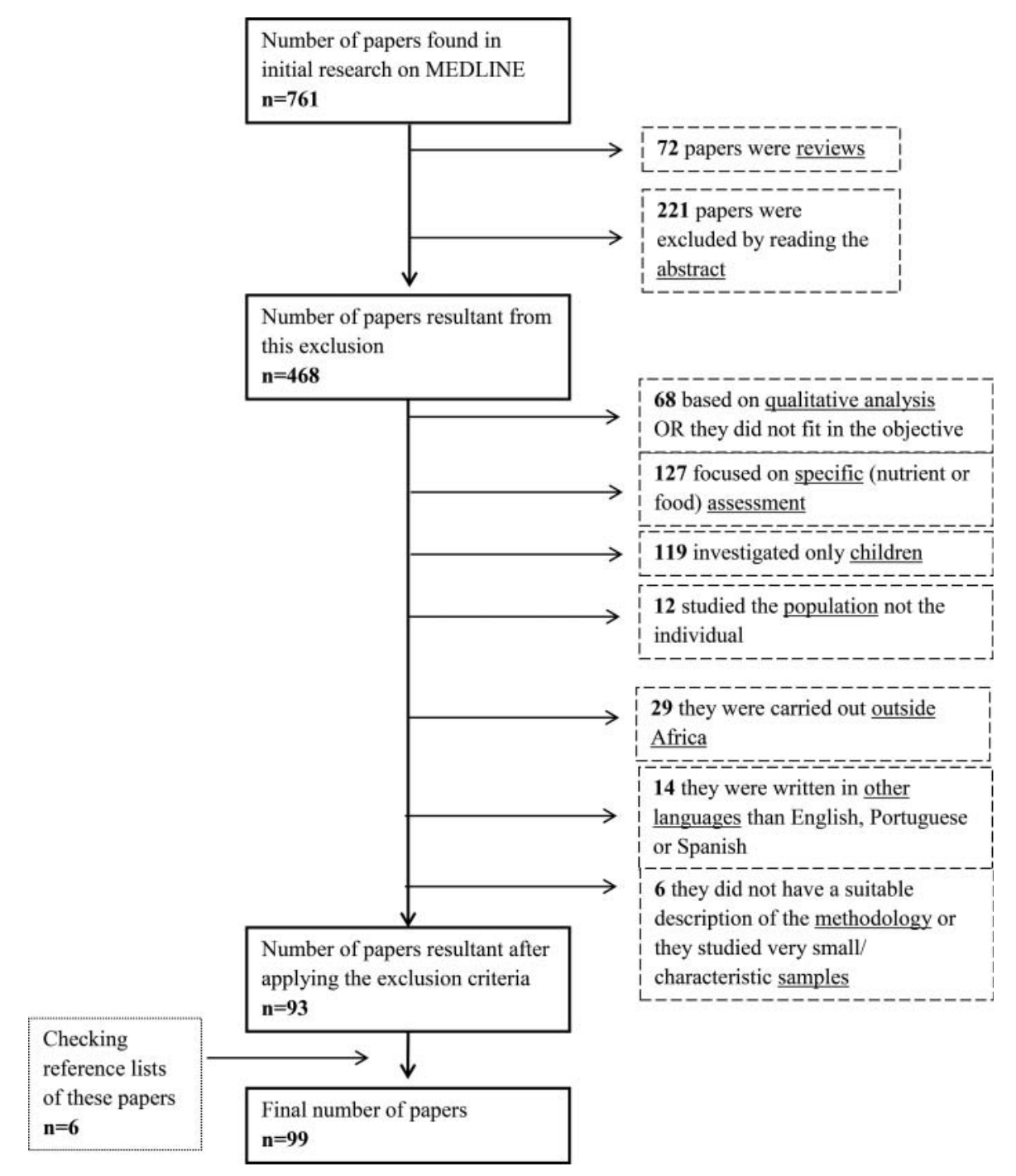

Figure 1. Flowchart of the paper's selection procedure.

tools need to be reproducible and valid in order to assure the consistency and accuracy of measurements (Willet, 1998). The choice of an appropriate method will depend on the aims of the study, the population approached as well as the research team's experience.

This systematic review intends to summarize the most recent research conducted in this field in African countries, specifically in what concerns the most used methodologies and tools.

\section{Methods}

The literature search was conducted on MEDLINE ${ }^{\circledR} / \mathrm{PubMed}$ in order to identify scientific papers focused on studies about dietary intake of different populations, among African countries. This research considers several African countries, from North, East, West, Central and South Africa. In order to narrow down and systematize the search in more recent literature, only original papers published between January 2005 and December 2014 were considered and specific key MeSH terms were used: dietary intake; Africa.

Several papers were identified but not all were considered for the systematic review. The inclusion criteria established were related to: the objective of the study: only studies intending to assess dietary intake; the methodology: only studies with a suitably described methodology; and the language: only papers written in English, Portuguese and Spanish. The exclusion criteria were: studies carried out among African people but not in African countries (for example, African immigrants in other countries); assessment of a particular nutrient or a specific food or food toxin; nonquantitative assessment of the diet; dietary assessment among children; and studies performed at household level. Studies that were focused on micronutrient assessment but further evaluated the contribution of macronutrients were also considered. Figure 1 shows a flowchart representing the paper's selection procedure.

A total of 761 studies were identified in the initial search by using the combination of the key terms mentioned above. Out of these, 221 were excluded by reading the abstract while 72 were reviews that were not included in the present study. After applying exclusion criteria, 68 papers were excluded because they did not involve a quantitative analysis or they did not comply to the established objective, 127 studies were related to a single nutrient or food, 119 investigated only children, 12 
CRITICAL REVIEWS IN FOOD SCIENCE AND NUTRITION

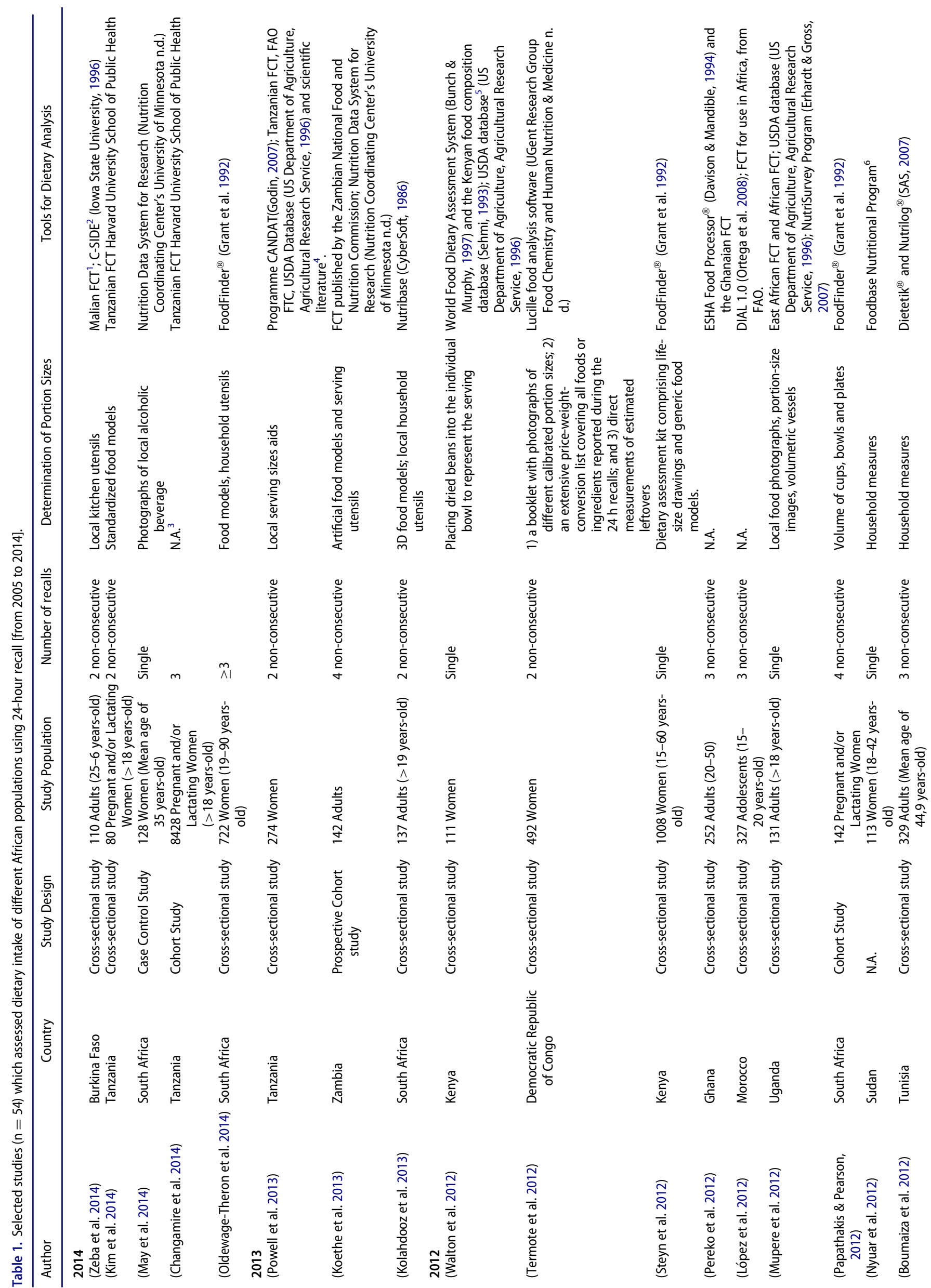



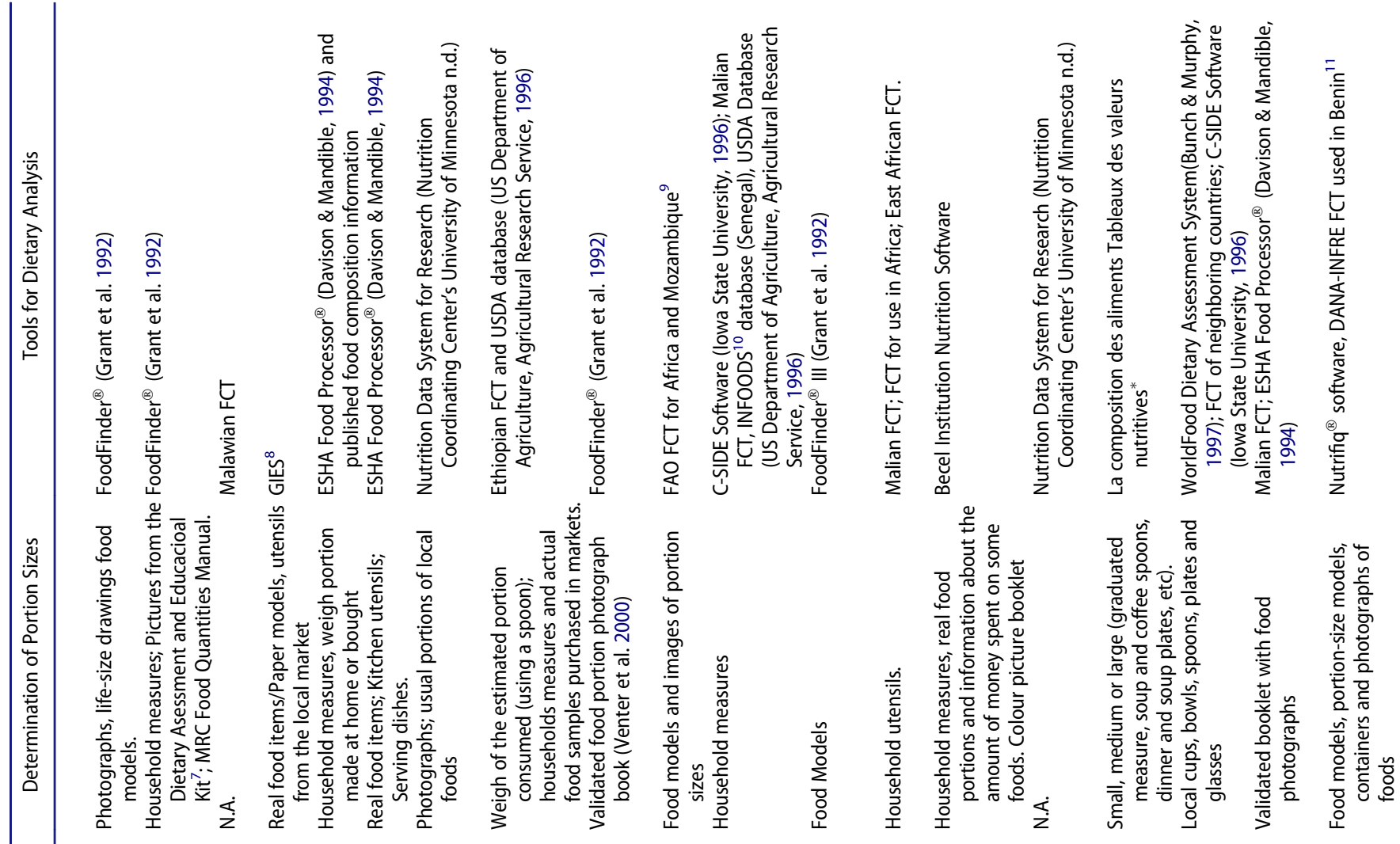

$\stackrel{2}{3}$

总

离

竎

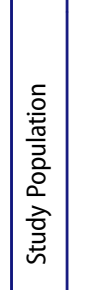

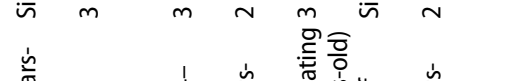

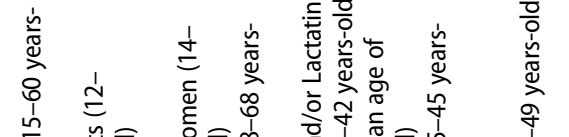

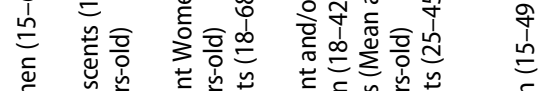

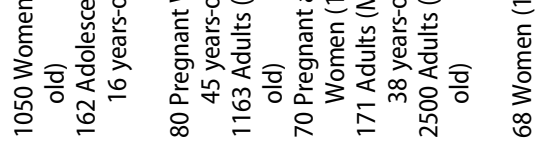

㟒

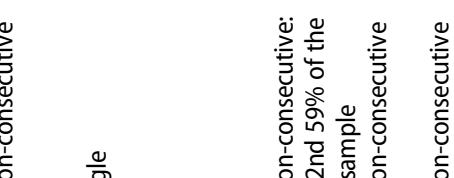

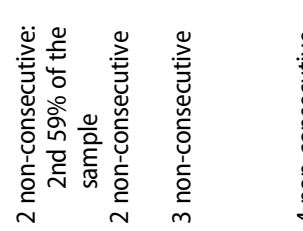

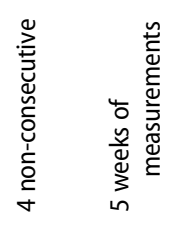

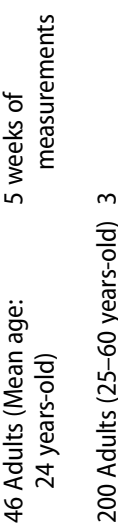

$\widehat{m}$

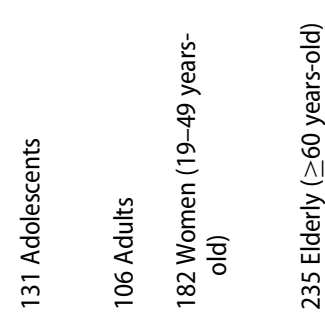

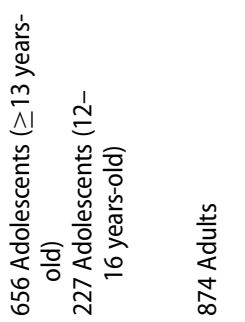

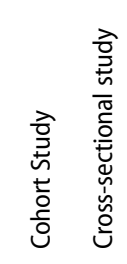

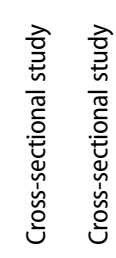

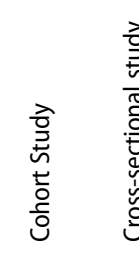

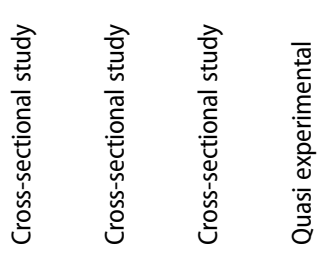

른

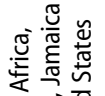

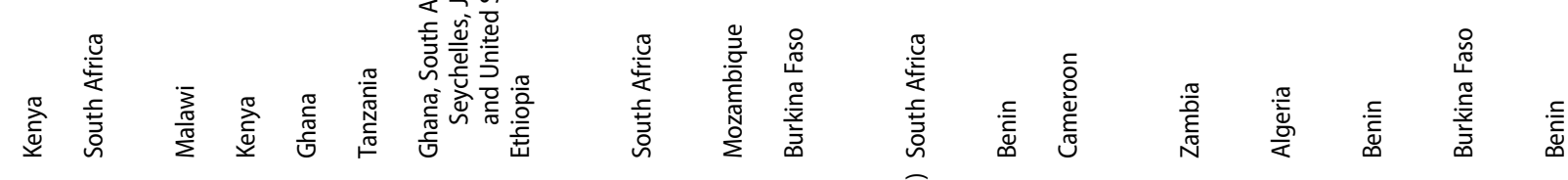

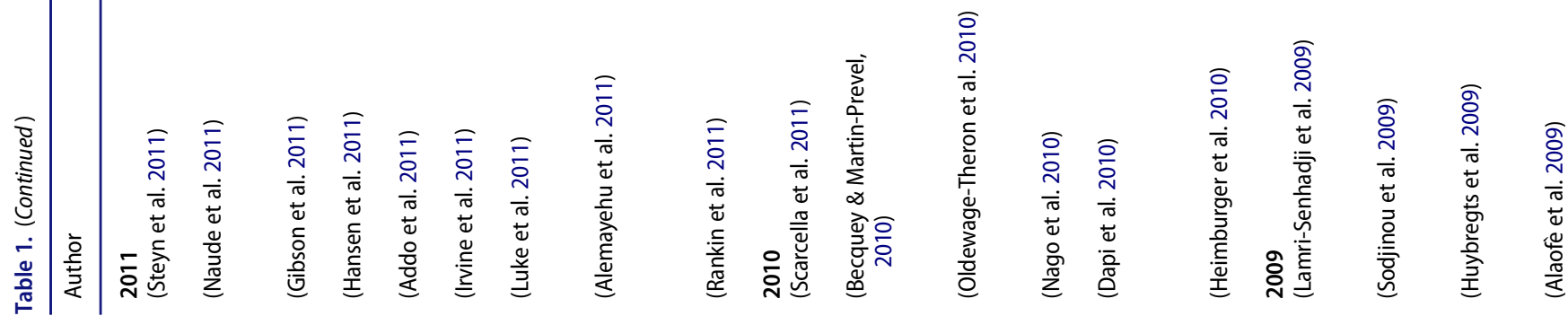




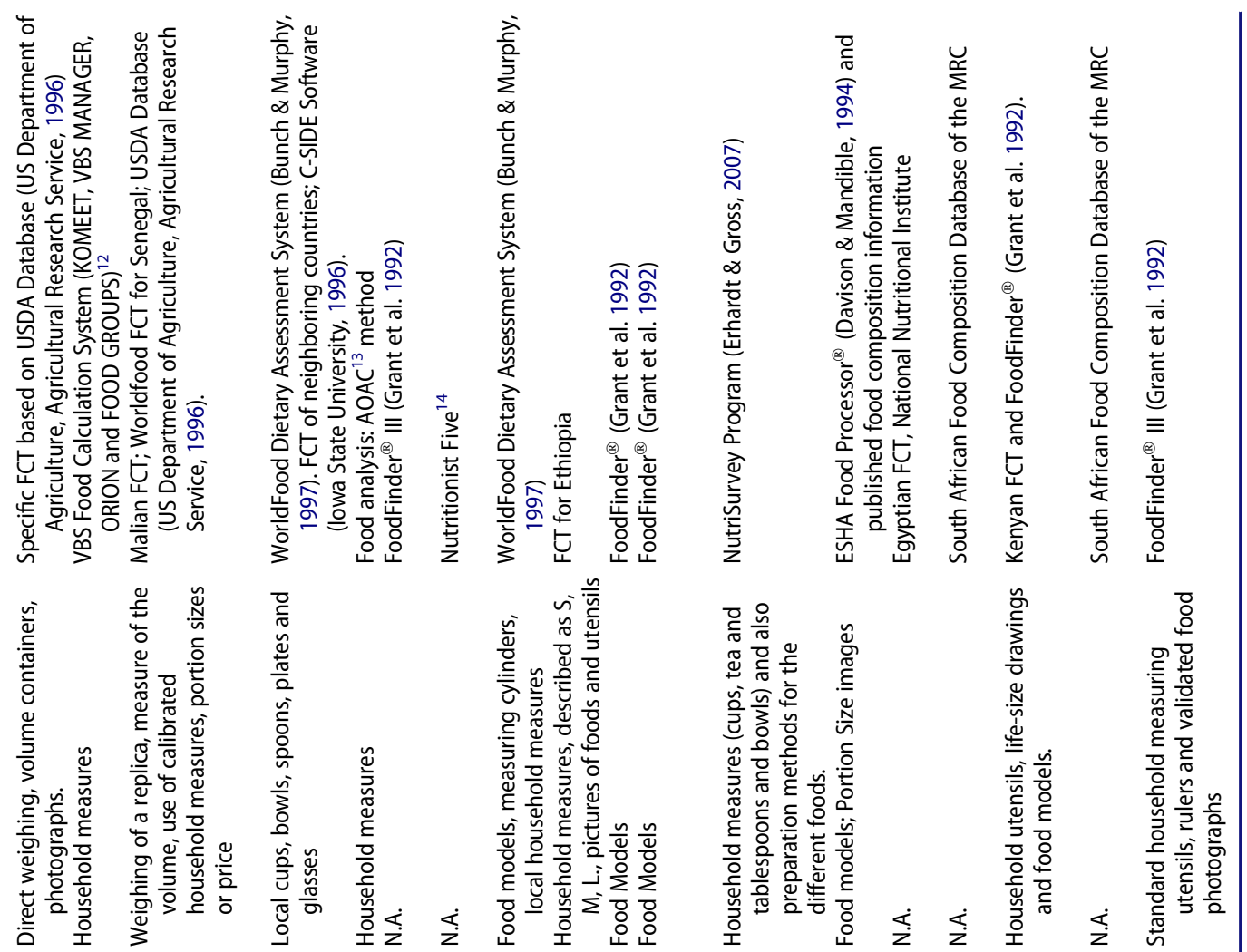

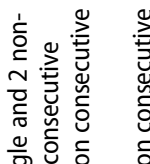

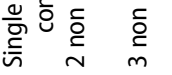

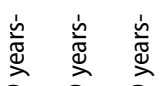

की

约

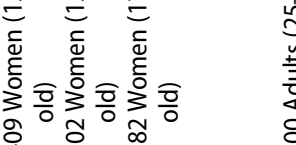

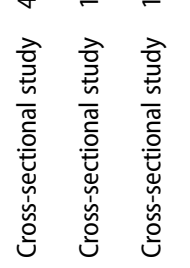

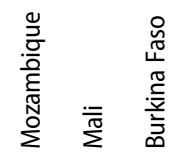

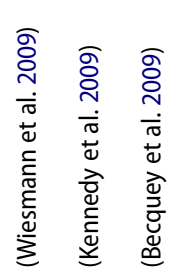

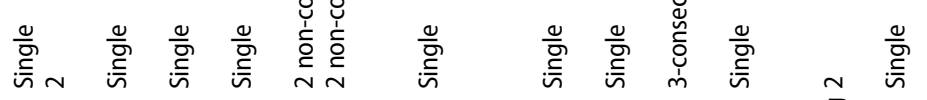

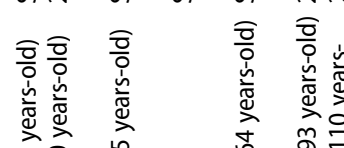

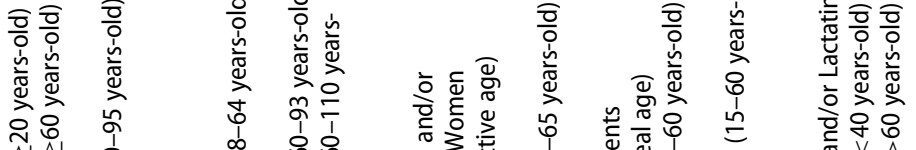

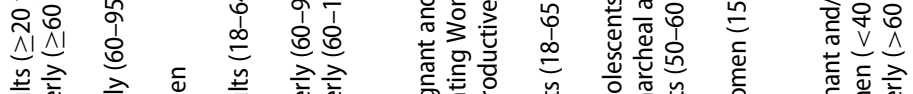

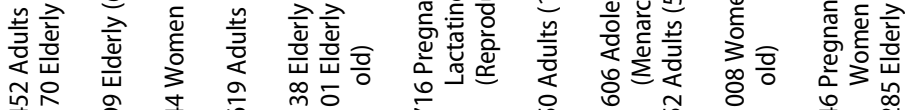

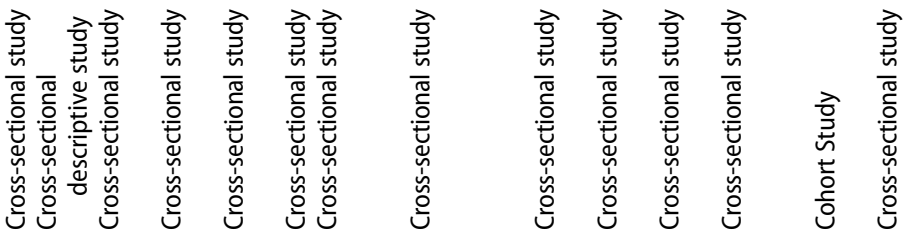


were not performed at an individual level, 29 were carried out outside Africa, 14 were written in other languages than English, Portuguese or Spanish, six did not have a suitable description of the methodology or were carried out in very small and characteristic samples. By checking the reference lists of each of these papers, another six papers, which complied with the inclusion criteria, were identified. Thus, the final number of papers was 99. Tables 1-4 summarize the main methodological issues of the included studies, allowing a comprehensive comparison between them. Papers were divided in the four tables according to the method used for dietary assessment: $24 \mathrm{hR}$ (Table 1) FFQ (Table 2), both 24hR, and FFQ (Table 3) and WR (Table 4). In each table, in addition to information about the country where the study was conducted and the year of publication, information about methodological issues, such as the study design, studied sample, dietary assessment methods and particularities are presented. Besides these aspects, the sampling methodology and main limitations of the studies were summarized in order to understand the most difficult challenges that researchers found in the field. Furthermore, the application of innovative technologies on dietary assessment in African countries was explored.

\section{Results}

The research retrieved 99 papers (102 studies) carried out among different African populations, namely adults (men and/ or women), adolescents and elderly people.

The included papers describe studies from twenty-two different countries, located in different African regions: Algeria $(\mathrm{n}=1)$, Egypt $(\mathrm{n}=1)$, Morocco $(\mathrm{n}=2)$, Sudan $(\mathrm{n}=1)$ and Tunisia $(n=5)$ (Northern Africa), Ethiopia $(n=6)$, Kenya $(\mathrm{n}=10)$, Malawi $(\mathrm{n}=1)$, Mozambique $(\mathrm{n}=3)$, Uganda $(\mathrm{n}=$ 3), Tanzania $(\mathrm{n}=7)$, Zambia $(\mathrm{n}=2)$ and Zimbabwe $(\mathrm{n}=1)$ (Eastern Africa), Benin $(\mathrm{n}=4)$, Burkina Faso $(\mathrm{n}=4)$, Ghana $(\mathrm{n}=4)$, Mali $(\mathrm{n}=1)$ and Nigeria $(\mathrm{n}=2)$ (Western Africa), Botswana $(\mathrm{n}=2)$, and South Africa $(\mathrm{n}=38)$, (Southern Africa), Cameroon $(n=3)$ and Democratic Republic of the Congo $(\mathrm{n}=1)$ (Central Africa), each region representing $10 \%$ $(\mathrm{n}=10), 32 \%(\mathrm{n}=33), 15 \%(\mathrm{n}=15)$, and 39\% $(\mathrm{n}=40)$, and $4 \%(n=4)$ of the total sample, respectively. The huge representation of Southern Africa is caused by the high number of studies developed in South Africa, representing 37\% $(n=38)$ of the included papers. This division of African regions is based on United Nation (UN) Statistics Division.

\section{Dietary assessment methods}

Almost all of these studies are cross-sectional studies, which capture the dietary practices in a specific population, at a particular point in time (Thompson and Byers, 1994; Gibson, 2005).

Overall, the two most used dietary assessment tools were the $24 \mathrm{hR}$ and the FFQ, which were applied separately or together. Among the studies, most of them $(\mathrm{n}=54)$ only used $24 \mathrm{hR}$ and in some cases the authors chose a single day of recall $(\mathrm{n}=20)$ (Charlton et al., 2005; Steyn and Nel, 2006; Kamau-Mbuthia and Elmadfa, 2007; Mounir et al., 2007; Wiig and Smith, 2007; Gewa et al., 2008; Ijarotimi and Keshinro, 2008; Maruapula and Chapman-Novakofski, 2008; Tesfaye et al., 2008;
Huybregts et al., 2009; Wiesmann et al., 2009; Alemayehu et al., 2011; Irvine et al., 2011; Scarcella et al., 2011; Steyn et al., 2011; Mupere et al., 2012; Nyuar et al., 2012; Steyn et al., 2012; Walton et al., 2012; May et al., 2014), whilst others utilized multiple recalls ( $\mathrm{n}=34$ ) (Mostert et al., 2005; O'Keefe et al., 2007; Oldewage-Theron et al., 2008; Oldewage-Theron et al., 2008; Oldewage-Theron et al., 2008; Sodjinou et al., 2008; Alaofe et al., 2009; Becquey et al., 2009; Kennedy et al., 2009; Lamri-Senhadji et al., 2009; Sodjinou et al., 2009; Becquey and Martin-Prevel, 2010; Dapi et al., 2010; Heimburger et al., 2010; Nago et al., 2010; Oldewage-Theron et al., 2010; Addo et al., 2011; Gibson et al., 2011; Hansen et al., 2011; Luke et al., 2011; Naude et al., 2011; Rankin et al., 2011; Boumaiza et al., 2012; López et al., 2012; Papathakis and Pearson, 2012; Pereko et al., 2012; Termote et al., 2012; Koethe et al., 2013; Kolahdooz et al., 2013; Powell et al., 2013; Changamire et al., 2014; Kim et al., 2014; Oldewage-Theron et al., 2014; Zeba et al., 2014), covering a range of two to eight recalls. One study did not mention the use of a $24 \mathrm{hR}$, however the described procedure allows us to conclude that this was the methodology followed (Tesfaye et al., 2008). Some studies (Maruapula and ChapmanNovakofski, 2008; Sodjinou et al., 2008; Alaofê et al., 2009; Becquey et al., 2009; Sodjinou et al., 2009; Wiesmann et al., 2009; Becquey and Martin-Prevel, 2010; Alemayehu et al., 2011; Luke et al., 2011; Termote et al., 2012; Powell et al., 2013; Kim et al., 2014; Zeba et al., 2014) followed a validated method for collecting interviewer-administered $24 \mathrm{hR}$, the so called United States Department of Agriculture (USDA) Automated Multiple-Pass Method (AMPM), which is a computerized method that can be applied in person or by telephone. Five other studies (Oldewage-Theron et al., 2008; Oldewage-Theron et al., 2008; Namugumya and Muyanja, 2011; Walton et al., 2012; Oldewage-Theron et al., 2014) mentioned other validated methods, one based on four steps developed by Gibson and Ferguson (1999) and Gibson (2005), and another one which is a $24 \mathrm{hR}$ questionnaire developed and validated by Oldewage-Theron et al. (2005). All the dietary information collected from these studies using the $24 \mathrm{hR}$ reference tool is summarized in Table 1.

In some papers $(n=30)$, authors selected only the FFQ for the dietary assessment (Kesa and Oldewage-Theron, 2005; Merchant et al., 2005; Belgnaoui and Belahsen, 2006; Hattingh et al., 2006; Jackson et al., 2007; MacKeown et al., 2007; Oguntibeju et al., 2007; Vorster et al., 2007; Hogenkamp et al., 2008; Tessier et al., 2008; Goedecke et al., 2009; Zingoni et al., 2009; Joffe et al., 2010; Anderson et al., 2011; Aounallah-Skhiri et al., 2011; Delport et al., 2011; Joffe et al., 2011; Kruger et al., 2011; Wentzel-Viljoen et al., 2011; Jackson et al., 2012; Joffe et al., 2012; Kruger et al., 2012; Pisa et al., 2012; Pretorius et al., 2012; Jordan et al., 2013; Lukmanji et al., 2013; Sheehy et al., 2013; Baroudi et al., 2014; Botha et al., 2014; Wrottesley et al., 2014), using either quantitative FFQ $(n=23)$ (Kesa and OldewageTheron, 2005; Belgnaoui and Belahsen, 2006; Hattingh et al., 2006; Jackson et al., 2007; Oguntibeju et al., 2007; Vorster et al., 2007; Hogenkamp et al., 2008; Tessier et al., 2008; Goedecke et al., 2009; Zingoni et al., 2009; Joffe et al., 2010; Anderson et al., 2011; Joffe et al., 2011; Kruger et al., 2011; WentzelViljoen et al., 2011; Jackson et al., 2012; Joffe et al., 2012; Kruger et al., 2012; Pisa et al., 2012; Pretorius et al., 2012; Sheehy et al., 
CRITICAL REVIEWS IN FOOD SCIENCE AND NUTRITION

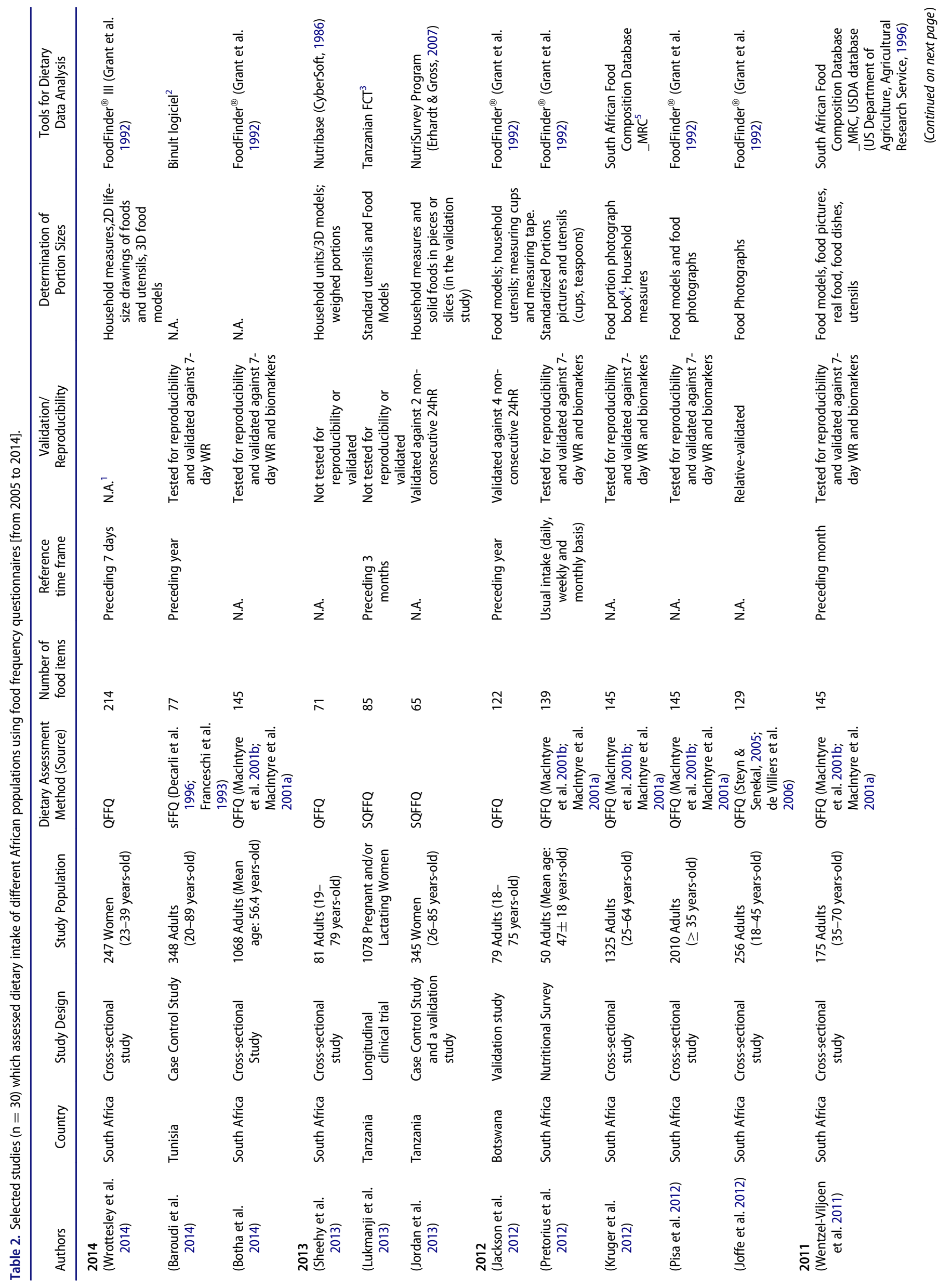




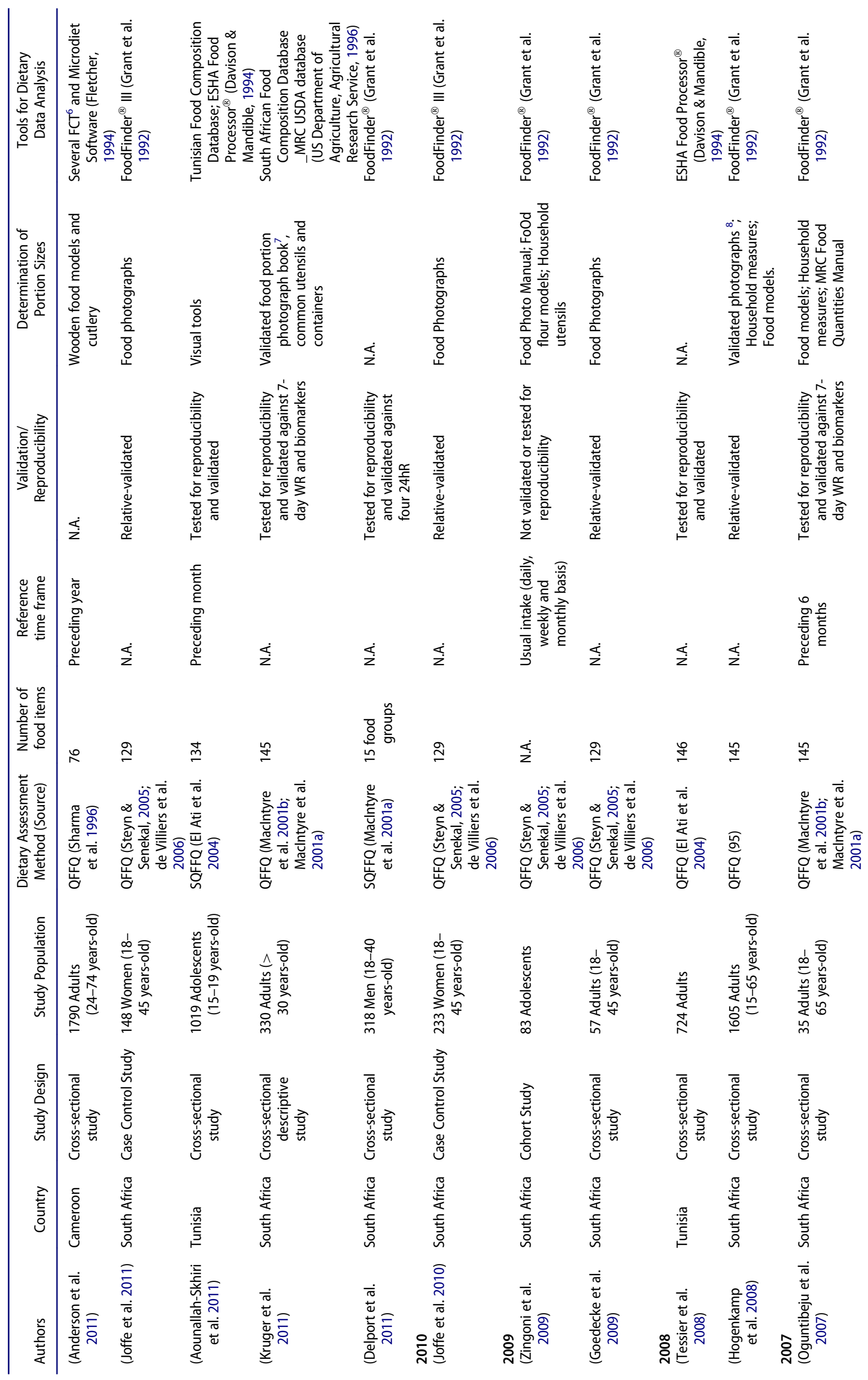



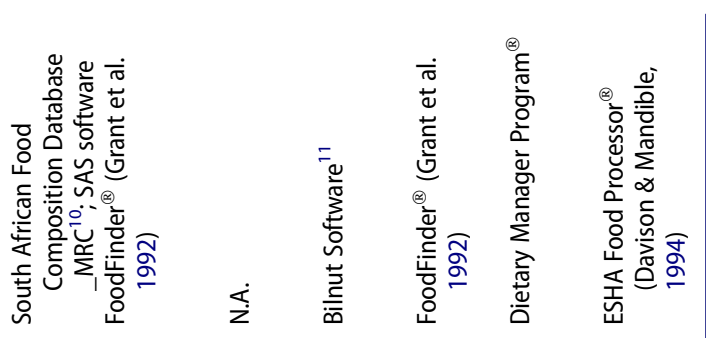

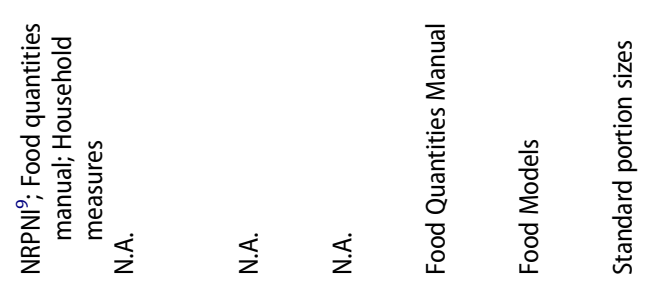

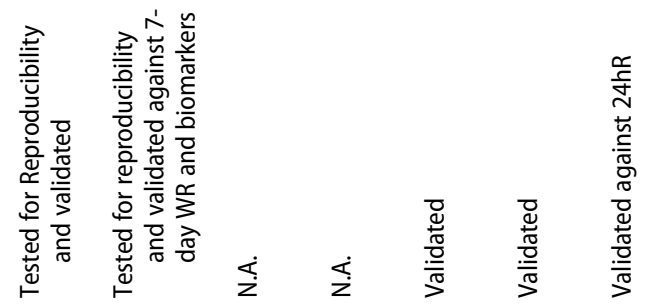

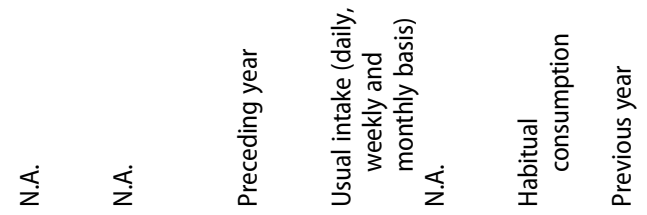

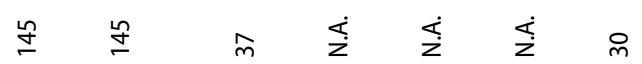

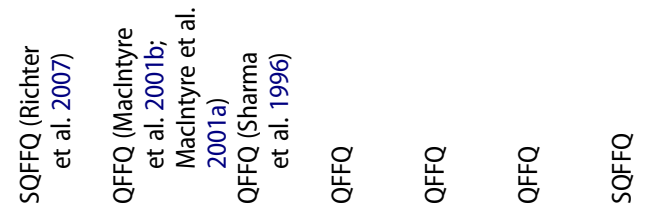

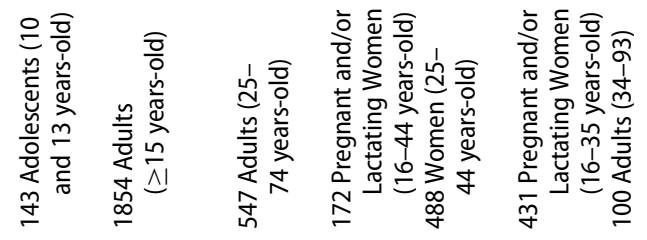

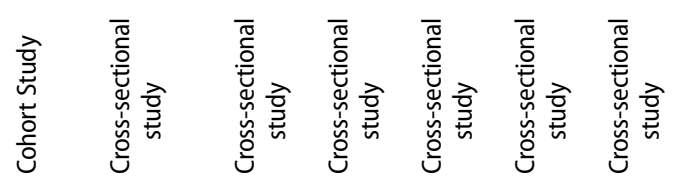

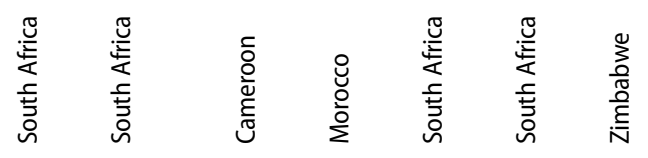

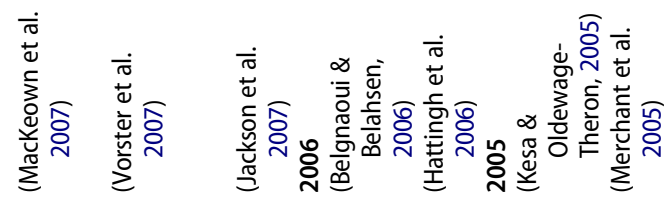

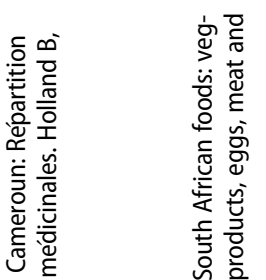

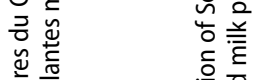

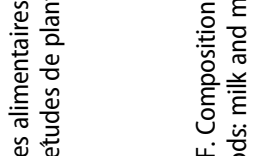

ㄴ.

으은

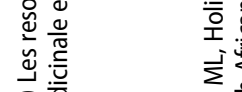

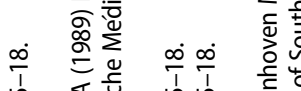

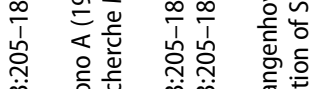

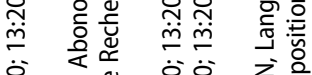

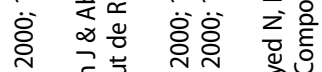

蓠

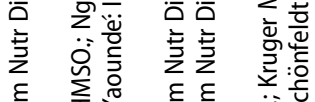

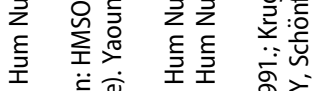

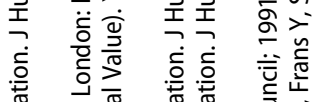

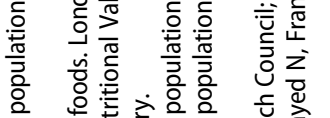

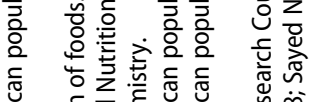

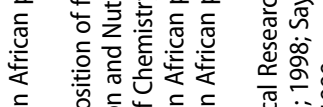

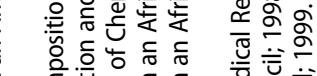

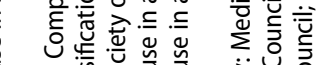

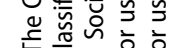

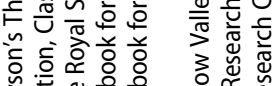

3 흔

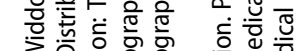

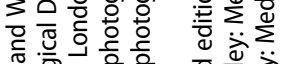

过 흥

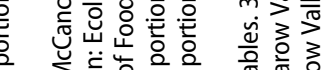

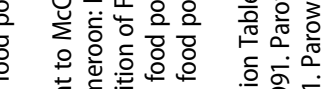

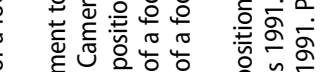

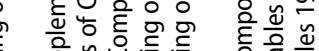

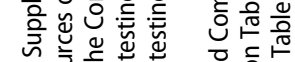

论

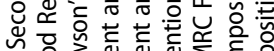

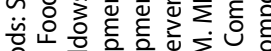

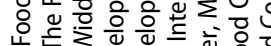

究

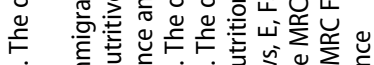

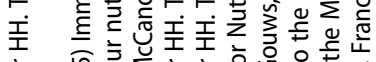

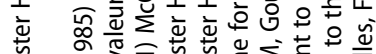

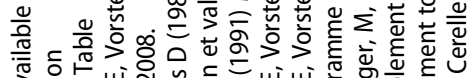

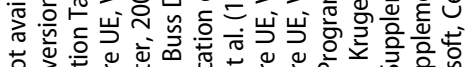

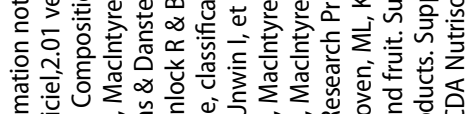

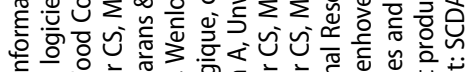

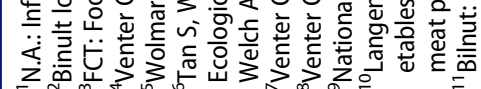




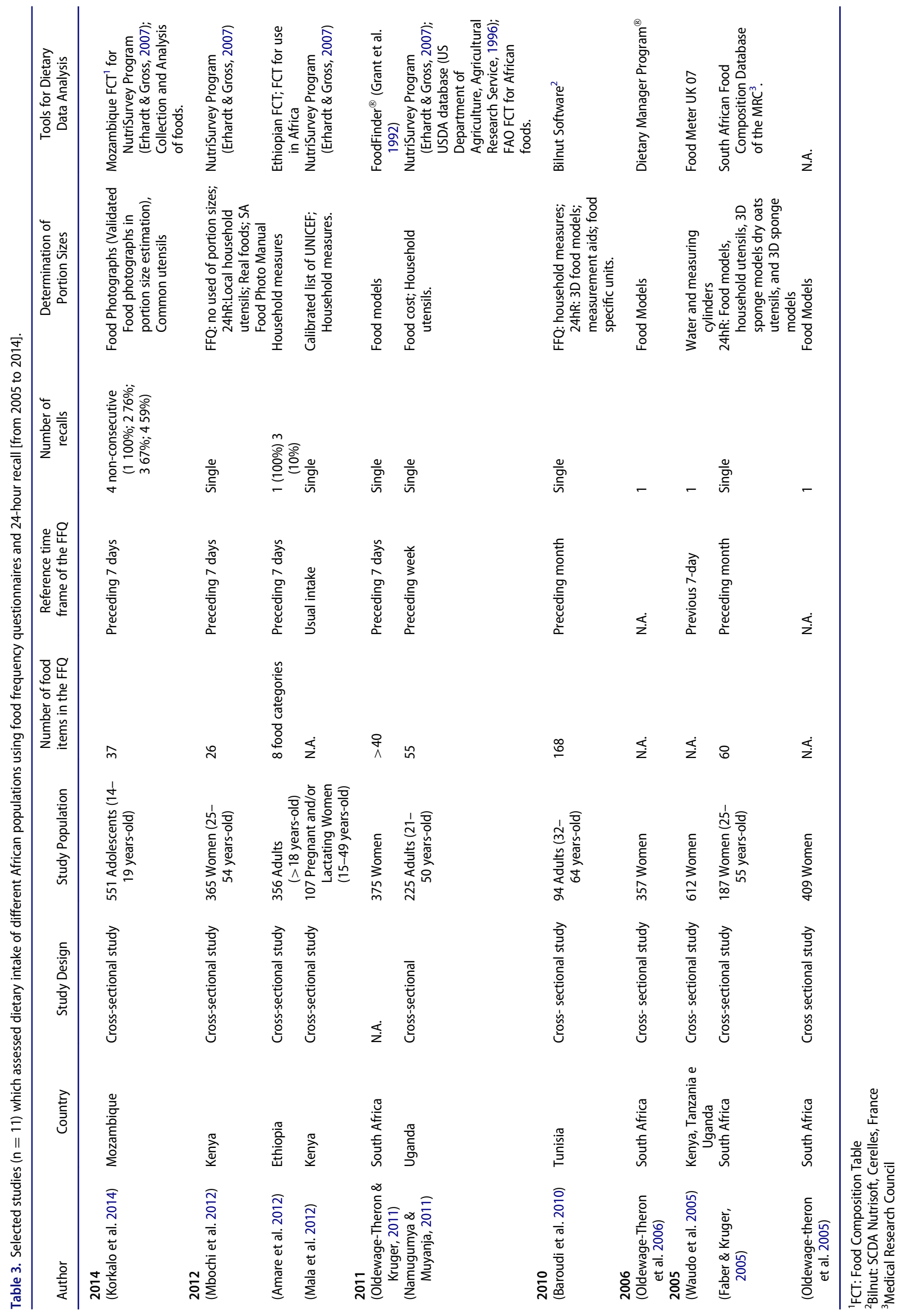


Table 4. Selected studies $(n=4)$ which assessed dietary intake of different African populations using weight records [from 2005 to 2014 ].

\begin{tabular}{|c|c|c|c|c|c|c|}
\hline Author & Country & Study Design & Study Population & Number of days & $\begin{array}{l}\text { Other collected } \\
\text { information }\end{array}$ & $\begin{array}{l}\text { Tools for Dietary Data } \\
\text { Analysis }\end{array}$ \\
\hline $\begin{array}{l}2013 \\
\text { (Haileslassie et al. } \\
\text { 2013) }\end{array}$ & Ethiopia & $\begin{array}{l}\text { Cross-sectional } \\
\text { study }\end{array}$ & $\begin{array}{l}60 \text { Pregnant and/or } \\
\text { Lactating Women } \\
\text { (15-49 years-old) }\end{array}$ & 1 day & $\begin{array}{l}\text { Description of the foods } \\
\text { and their cooking } \\
\text { methods }\end{array}$ & $\begin{array}{l}\text { ESHA Food Processor }^{\circledR} \\
\text { (Davison \& Mandible } \\
\text { 1994); Ethiopian FCT }\end{array}$ \\
\hline $\begin{array}{l}2012 \\
\text { (Olayiwola et al. } \\
\text { 2012) }\end{array}$ & Nigeria & $\begin{array}{l}\text { Cross-sectional } \\
\text { study }\end{array}$ & $\begin{array}{l}240 \text { Elderly } \\
\quad(>60 \text { years-old })\end{array}$ & 3 consecutive days & $\begin{array}{l}\text { Description of the what } \\
\text { was eaten on the day } \\
\text { before }\end{array}$ & $\begin{array}{l}\text { FAO FCT; Total Dietary } \\
\text { Assessment Software } \\
\text { (NUTRIDATA)(Pirone \& } \\
\text { et al. 1993) }\end{array}$ \\
\hline $\begin{array}{l}2008 \\
\text { (Gibson et al. } \\
\text { 2008) }\end{array}$ & Ethiopia & $\begin{array}{l}\text { Cross-sectional } \\
\text { study }\end{array}$ & $\begin{array}{l}99 \text { Women (Mean age: } \\
27,8 \text { years-old) }\end{array}$ & 1 day & N.A. & Ethiopian FCT \\
\hline $\begin{array}{l}\text { (Abebe et al. } \\
\text { 2008) }\end{array}$ & Ethiopia & $\begin{array}{l}\text { Cross-sectional } \\
\text { study }\end{array}$ & $\begin{array}{l}99 \text { Women (Mean age: } \\
27,8 \text { years-old) }\end{array}$ & $\begin{array}{l}2 \text { non-consecutive } \\
\text { days }\end{array}$ & $\begin{array}{l}\text { Detailed weighed recipe } \\
\text { data for all the } \\
\text { composite dishes }\end{array}$ & $\begin{array}{l}\text { Development of a database } \\
\text { based on the Ethiopian } \\
\text { FCT }\end{array}$ \\
\hline
\end{tabular}

${ }^{1} \mathrm{FCT}$ : Food Composition Table

2013; Botha et al., 2014; Wrottesley et al., 2014) or semi-quantitative FFQ $(\mathrm{n}=7)$ (Merchant et al., 2005; MacKeown et al., 2007; Aounallah-Skhiri et al., 2011; Delport et al., 2011; Jordan et al., 2013; Lukmanji et al., 2013; Baroudi et al., 2014). Several studies (Oguntibeju et al., 2007; Vorster et al., 2007; Hogenkamp et al., 2008; Goedecke et al., 2009; Zingoni et al., 2009; Joffe et al., 2010; Joffe et al., 2011; Kruger et al., 2011; Wentzel-Viljoen et al., 2011; Joffe et al., 2012; Kruger et al., 2012; Pisa et al., 2012; Pretorius et al., 2012; Botha et al., 2014; Wrottesley et al., 2014) developed in South Africa used a quantitative FFQ specific for the South African population, retrieved from two sources, namely the Transition Health and Urbanization in South Africa (THUSA) questionnaire, design by MacIntyre et al. (2001a, 2001b) and the Dietary Assessment and Education Kit (DAEK) questionnaire, developed by Steyn and Senekal and launched by the Medical Research Council (MRC) (Steyn and Senekal, 2005; de Villiers et al., 2006). Within the employment of quantitative food frequency questionnaires (FFQs), Jackson et al. (2007) and Anderson et al. (2011), used the questionnaire of Sharma et al. (1996), which was developed specifically for Cameroonian people, but no information about its validation was reported Kesa and Oldewage-Theron (2005) and Hattingh et al. (2006) also mentioned that they used a previously validated questionnaire, but no reference was made to any paper where the validation study was published. Belgnaoui and Belahsen (2006) did not specify if the used FFQ was validated or not. Within semi-quantitative FFQs, a study carried out in Tunisia (Baroudi et al., 2014) used a validated FFQ developed in Italy, which was designed for a population with similar characteristics; both populations had cancer (Franceschi et al., 1993; Decarli et al., 1996). The study of MacKeown et al. (2007) used a FFQ based on the one used in the Birth-To-Twenty study (Richter et al., 2007). Two other Tunisian studies (Tessier et al., 2008; Aounallah-Skhiri et al., 2011) used an already validated questionnaire (El Ati et al., 2004) with few modifications according to the studied population. There were other cases in which the authors developed their own quantitative questionnaires for implementation (Merchant et al., 2005; Jackson et al., 2012; Jordan et al., 2013; Lukmanji et al., 2013; Sheehy et al., 2013). For example, Sheehy et al. (2013) developed a specific FFQ for use among rural South Africans and Jackson et al. (2012) developed, validated and tested for reproducibility a FFQ for use among adults in Botswana. Jordan et al. (2013) and Merchant et al. (2005) developed semi-quantitative FFQs to assess dietary intake in Tanzanian women and in Zimbabwean population, respectively. Lukmanji et al. (2013), authors of a Tanzanian study, also developed their own semi-quantitative FFQ but gave no information about a validation study. It is possible to observe that there are few recent validated dietary assessment instruments for African populations. As mentioned, some of the studies described so far utilized questionnaires published before 2005 have been used for dietary assessment (Sharma et al., 1996; El Ati et al., 2004), in the reviewed studies. In other cases, questionnaires were obtained from the Demographic and Health Surveys in the correspondent country. Table 2 summarizes characteristics of all the studies which used an FFQ to measure the dietary intake.

Several studies used a combination of both methods ( $\mathrm{n}=11$ ), (Faber and Kruger, 2005; Oldewage-theron et al., 2005; Waudo et al., 2005; Oldewage-Theron et al., 2006; Baroudi et al., 2010; Namugumya and Muyanja, 2011; Oldewage-Theron and Kruger, 2011; Amare et al., 2012; Mala et al., 2012; Mbochi et al., 2012; Korkalo et al., 2014), as synthesized in Table 3. Namugumya and Muyanja (2011), applied 24hR aiming to study meal patterns and to assess meal quality, whereas with the application of a FFQ they intended to gather information on food selection patterns and portion sizes. Oldewage-theron et al. (2005) used the FFQ to study both quantitative and qualitative food consumption patterns and dietary intake of the respondents and they validated this FFQ using 24-hour recalls as a gold standard. This questionnaire was later used in 2006 by Oldewage-Theron et al. (2006). Korkalo et al. (2014), developed their own questionnaire and Mala et al. (2012) used a pre-existent FFQ (without mentioning its source) to gather information about frequency of food consumption while the $24 \mathrm{hR}$ was used to quantify the dietary intake. Faber and Kruger (2005), Amare et al. (2012), Mbochi et al. (2012) used a qualitative FFQ and $24 \mathrm{hR}$ to determine nutritional intake, while Oldewage-Theron and Kruger (2011) used a quantitative FFQ to assess dietary intake and food consumption patterns and a $24 \mathrm{hR}$ to confirm food variety and 
dietary intake. The questionnaire used by Amare et al. (2012) was based on the Hellen Keller International FFQ, previously used in Ethiopia. Baroudi et al. (2010) assessed dietary intake using a quantitative FFQ and performed $24 \mathrm{hR}$ in order to obtain more qualitative information, related to food brand names and food preparation methods. Waudo et al. (2005) used $24 \mathrm{hR}$ to assess what mothers had eaten in the preceding $24 \mathrm{~h}$ and then applied an FFQ in order to obtain information about the types of foods commonly consumed.

Besides these two retrospective methods, weighed records were also utilized, but in a much smaller number; only four studies. Haileslassie et al. (2013) and Gibson et al. (2008) used only a single day as a measuring unit while Olayiwola et al. (2012) and Abebe et al. (2008) applied food records for three and two nonconsecutive days, respectively. More detailed information about these studies is compiled in Table 4.

\section{Methods for the analysis of food intake data}

A large range of software tools for the analysis of dietary data were mentioned in these studies. According to Table 5 it can be observed that there is a preferential selection of food databases of the countries within the same African region. For instance, in Western Africa the Software for Intake Distribution Estimation (C-SIDE) developed by Iowa State University is commonly used, while in Eastern Africa, NutriSurvey is the mainly chosen software. In the Northern African countries, Bilnut Software was used for the majority and in the South, FoodFinder ${ }^{\circledR}$ (Grant et al., 1992) was clearly the most utilized software. Several countries had to update these tools with their own typical foods or recipes of composite dishes, when these were not available.

In Western African countries the most used nutritional programs were ESHA Food Processor ${ }^{\circledR}$ (Food Processor Diet Analysis and Fitness Software) (Wiig and Smith, 2007; Huybregts et al., 2009; Addo et al., 2011; Pereko et al., 2012) and C-SIDE (Sodjinou et al., 2008; Sodjinou et al., 2009; Becquey and Martin-Prevel, 2010; Zeba et al., 2014). Several authors used other softwares, such as NutriData, developed in California (Olayiwola et al., 2012), Nutrition Data System for Research (NDSR), developed by University of Minnesota (Luke et al., 2011) and Nutrifiq, based on the Canadian Nutrient File (Alaofe et al., 2009). A very comprehensive software system, named VBS Food Calculation System, was chosen for the Women's Dietary Diversity Project (in Burkina Faso and Mali) (Becquey et al., 2009; Kennedy et al., 2009). VBS Food Calculation System is a set of three softwares, which include KOMEET (for food intake analysis), VBS MANAGER (nutrient composition information), ORION and FOOD GROUPS (both for nutrient intake by food group analysis).

In East Africa, almost all the studies performed therein used the NutriSurvey Program, which has seventeen different food databases (food composition tables from Tanzania, Kenya, Senegal, Mali and Germany among others) (Kamau-Mbuthia and Elmadfa, 2007; Namugumya and Muyanja, 2011; Mala et al., 2012; Mbochi et al., 2012; Mupere et al., 2012; Jordan et al., 2013; Korkalo et al., 2014). ESHA Food Processor ${ }^{\circledR}$ (Merchant et al., 2005; Irvine et al., 2011; Haileslassie et al., 2013), FoodFinder $^{\circledR}$ (Steyn and Nel, 2006; Steyn et al., 2011; Steyn et al., 2012), which includes the latest version of the South African Food Composition Database, NDSR (Heimburger et al., 2010; Koethe et al., 2013), and WorldFood Dietary Assessment System (Gewa et al., 2008; Walton et al., 2012) were also used. Softwares such as Programme CANDAT (Powell et al., 2013), Food Meter UK 07 (Waudo et al., 2005) and General Intake Estimation System, developed by The National Food Institute, in Denmark (Hansen et al., 2011) (linked with Composition of Foods Commonly Eaten in East Africa, the UK Nutrient Databank and National Food Composition Tables and The Planning of Satisfactory Diets in Kenya), were also chosen for nutrient analysis.

Northern African countries based their nutrient analysis on Bilnut Software (Belgnaoui and Belahsen, 2006; Baroudi et al., 2010; Baroudi et al., 2014). However, other softwares such as ESHA Food Processor ${ }^{\circledR}$ (Aounallah-Skhiri et al., 2011), DIAL Programme (López et al., 2012), developed by several authors from Alce Ingenieria, Tableaux des valeurs nutritives (Lamri-Senhadji et al., 2009), built by Souci et al. (2000), Dietetik $^{\circledR}$, designed for Tunisian foods, Nutrilog ${ }^{\circledR}$, a software with eleven different databases (Boumaiza et al., 2012) and FoodBase Nutritional Program (Nyuar et al., 2012) were also used in some studies.

Investigations carried out in South African countries mainly used FoodFinder ${ }^{\circledR}$ software(Charlton et al., 2005; Faber and Kruger, 2005; Mostert et al., 2005; Hattingh et al., 2006; O'Keefe et al., 2007; Oguntibeju et al., 2007; Vorster et al., 2007; Oldewage-Theron et al., 2008; Oldewage-Theron et al., 2008; Oldewage-Theron et al., 2008; Zingoni et al., 2009; Joffe et al., 2010; Oldewage-Theron et al., 2010; Joffe et al., 2011; Kruger et al., 2011; Naude et al., 2011; Oldewage-Theron and Kruger, 2011; Rankin et al., 2011; Wentzel-Viljoen et al., 2011; Jackson et al., 2012; Kruger et al., 2012; Papathakis and Pearson, 2012; Pretorius et al., 2012; Oldewage-Theron et al., 2014; Wrottesley et al., 2014).

Other software databases such as NDSR (May et al., 2014), NutriBase (Kolahdooz et al., 2013; Sheehy et al., 2013), developed by CyberSoft (both based on USDA National Nutrient Database for Standard Reference), Dietary Manager Program ${ }^{\circledR}$ (Kesa and Oldewage-Theron, 2005; Oldewage-Theron et al., 2006) managed by Oskar Scharf of Dietetic Services/Rand Software and Nutritionist Five (Maruapula and ChapmanNovakofski, 2008) were also used.

In Central Africa, the used software tools in Cameroon were Microdiet (Anderson et al., 2011) and Becel Institute Nutrition Software (Dapi et al., 2010) and Lucille food analysis software (Termote et al., 2012) in Democratic Republic of Congo.

Some studies did not mention the use of specific software, only referring the use of food composition databases, as source of information for the nutrient analysis, whose analysis was performed with a tool, such as Microsoft ${ }^{\circledR}$ Office Excel or IBM SPSS software for example, to compute dietary data.

Generally in African countries, there is a lack of countryspecific Food Composition Tables (FCTs), and the ones that have their own FCT, do not have it updated. For this reason some countries use FCTs from neighboring countries or use global databases. Examples of cited databases are: USDA Nutrient Database for Standard Reference and others developed by Food and Agriculture Organization (FAO), such as 
$\varepsilon$ ठิ

\section{离}

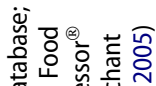

全比㐫的

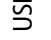
哭 隹

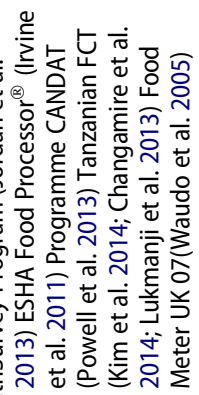
产

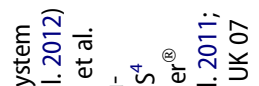

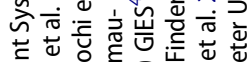

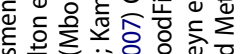

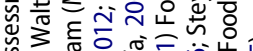

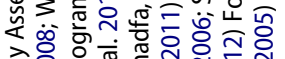

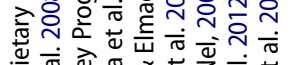

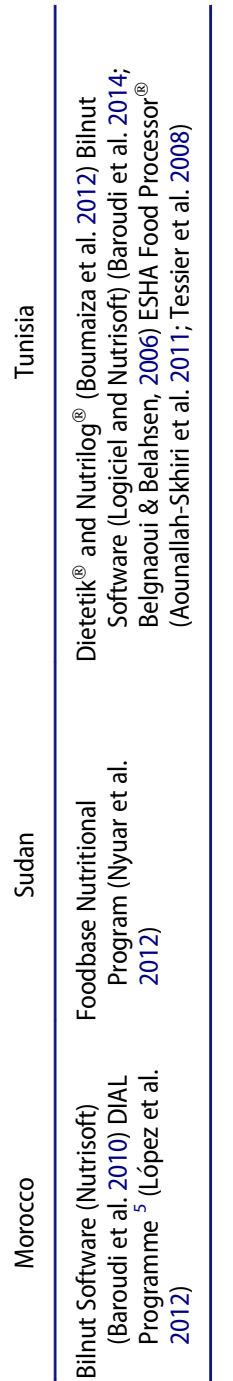

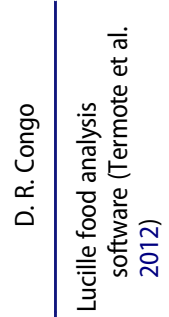

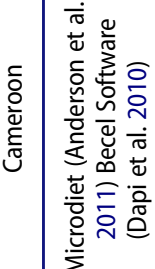

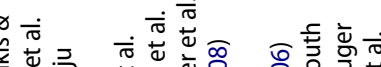

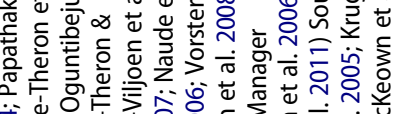

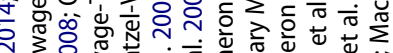

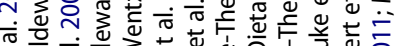

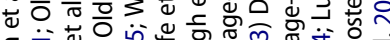

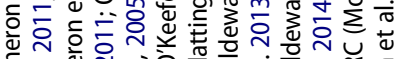

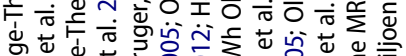

ख

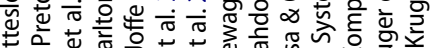

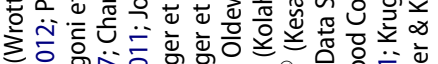

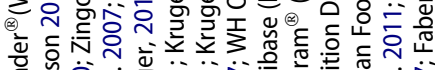

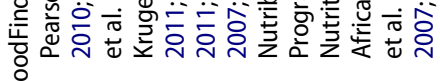

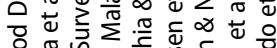

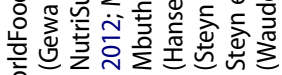

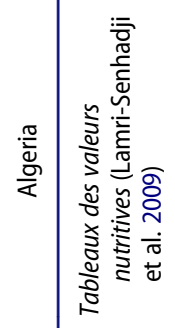

高

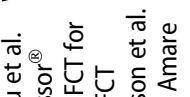

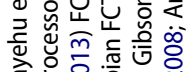

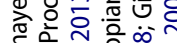

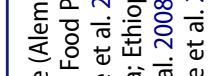

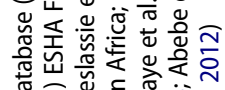

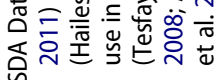
令
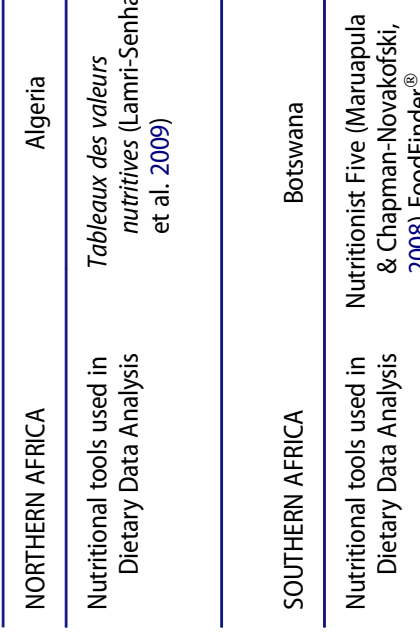
Food Composition Table for Use in Africa, West African Food Composition Table and Composition of Selected Foods from West Africa. USDA Database was the most cited database, in countries such as Burkina Faso, Cameroon, Ethiopia, Uganda, Zimbabwe, Cameroon or Botswana. All of these databases could be accessed on the International Network of Food Data Systems (INFOODS) directory.

\section{Sampling methodology}

Sampling can be done using different methodologies, depending on the aim of the investigation, on the sample size, among other factors.

According to the range of studied papers, random and nonrandom sampling methods were used, random sampling being the most common. Some authors did not describe how the recruitment of subjects was done. Within random sampling the main methods used were stratified sampling, multi-stage sampling and simple random sampling. Non-random convenience sampling was also used.

In studies using a multistage sampling approach, probability proportionate to size method was frequently used in the first selection stage, i.e., in the selection of areas (rural/urban), districts, villages, communities or even quarters. Consequently households were simply randomly selected (Oldewage-theron et al., 2005; Ijarotimi and Keshinro, 2008; Sodjinou et al., 2009; Nago et al., 2010; Amare et al., 2012; Olayiwola et al., 2012) or the walk method was used (Alemayehu et al., 2011; Korkalo et al., 2014), for the identification of the subject that fulfilled the inclusion criteria, within each household. Besides these walk methods, the usage of township maps to more easily select residential areas was also utilized as one of the initial methodologies of the sampling procedure (Hattingh et al., 2006; Oldewage-Theron and Kruger, 2011; Kolahdooz et al., 2013; Oldewage-Theron et al., 2014). Few studies (Becquey et al., 2009; Nago et al., 2010; Powell et al., 2013) mentioned the possibility to access residential information in the studied city, which were provided by state agencies, such as the village government, Ministry of Education or the Higher Institute of Population Science. Since it was possible to differentiate segments in populations, in several cases creation of clusters (Waudo et al., 2005; Tessier et al., 2008; Kennedy et al., 2009; Aounallah-Skhiri et al., 2011; Jackson et al., 2012) or stratification of the sample (Kesa and Oldewage-Theron, 2005; Steyn and Nel, 2006; Jackson et al., 2007; Mounir et al., 2007; Vorster et al., 2007; Hogenkamp et al., 2008; Maruapula and ChapmanNovakofski, 2008; Dapi et al., 2010; Anderson et al., 2011; Luke et al., 2011; Steyn et al., 2011; Mbochi et al., 2012; Steyn et al., 2012; Haileslassie et al., 2013; Powell et al., 2013) by environmental or individual factors, such as social strata, income, living in rural or urban area, age or sex, was performed. In some cases, participants were randomly recruited using advertisements which were placed in different and strategic locations, such as church groups, community centers and universities or even in local newspapers (Charlton et al., 2005; O'Keefe et al., 2007; Goedecke et al., 2009). Subjects were recruited in medical clinics, health centers or day care centers; in some papers random sampling was cited (Mostert et al., 2005; OldewageTheron et al., 2006; Jordan et al., 2013; Lukmanji et al., 2013) and in others no sampling method was mentioned (Belgnaoui and Belahsen, 2006; Wiig and Smith, 2007; Oldewage-Theron et al., 2008; Baroudi et al., 2010; Heimburger et al., 2010; Oldewage-Theron et al., 2010; Gibson et al., 2011; Kim et al., 2014).

Convenience sampling was applied in several studies (Abebe et al., 2008; Gibson et al., 2008; Joffe et al., 2012; Termote et al., 2012; Walton et al., 2012). In other cases, authors only mention that the sampling method was not random (Alaofe et al., 2009; Wrottesley et al., 2014).

\section{Discussion}

The purpose of this review was to summarize the methodologies and tools used in dietary intake assessment in African countries, in a ten year period, covering steps from the sampling to dietary data analysis.

When we seek to describe the dietary intake of a population, the first required step is to establish a representative sample. Many sampling and subject recruitment methods can be used and these were indeed reflected in the analyzed studies. The major part of the studies applied random recruitment. In the cases in which convenience sampling was performed, various segments of the population were not included and since it is not possible to calculate the total number of excluded people, it is also not possible to determine bias caused by the absence of these individuals in the sample (Gouveia de Oliveira, 2009). Ideally, random methods should be used when the aim is to characterize a population. In the recruitment process, the selected approaches have to be adapted to the population socio-economical and educational capabilities in order to assure adequate response rates and to avoid constraints in participation. The authors of the studies included in this review used some strategies, such as: the description of the study objectives in the population's native language, overcoming language limitations; the possibility to give oral consent for participation in the investigation, overlapping limitations related to high rates of illiteracy; and picking enumerators or volunteers that understood very well the population and their habits aiming to reach their confidence, reducing the possibility of anxiety or suspicion that could be present in such situations (Ngo et al., 2009).

\section{Dietary assessment methods}

Implementation of dietary assessment methods may be done in several ways, for instance face-to-face interviews, by telephone, by email, self-administrated or observation when using the weighing method. The selected implementation method is related mainly with social and economic context of the studied areas and the resources available for the research. In this review the majority of the included studies were performed with faceto-face interviews and in two cases, i.e. in South Africa and Cameroon, self-administration was used.

To understand which is the best methodology to choose according to the population and the purpose of the study, and considering that $24 \mathrm{hR}$ and FFQ methods rely on respondents' memory, it is important to evaluate the accuracy of memorybased reports. There is cognitive research that confirms that for general people it is easier to describe generic dietary patterns 
than to describe a specific dietary meal (Wirfalt, 1998). According to Thompson and Byers (1994), in cross-sectional studies generally the most used methodology is the $24 \mathrm{hR}$, as corroborated by this review. Furthermore, as shown in the analysis performed herein, FFQ was the second most used tool. Both have advantages and disadvantages and should be applicable in specific situations. In their review Pisa et al. (2014) also identified the same top chosen dietary assessment tools.

A single $24 \mathrm{hR}$ is an indepth-interview that must be administered by trained people. In some of the studies under revision the interviewer was either a nutritionist, a dietitian or a nutrition student who had been previously trained by experts to collect dietary data. Such extensive expert training of the interviewer in state-of-the-science methodology is of extreme importance for obtaining valid and reliable assessments and analyses of dietary intakes. Furthermore, the need for a broad perception and issue awareness is needed to successfully fulfill collection of dietary data using this method which is dependent on the subject's memory. A well-trained interviewer will create the need and relaxed atmosphere for the subject, as well as ask key questions that help subjects remember their intake easily (Willet, 1998). According to Wirfalt (1998), and also Smith and colleagues (Smith, 1991; Smith et al., 1991), more important than closeness of time or number of assessed days are the cues presented to the respondent, which influence aspects of the memory structure that are accessed or activated. There is evidence that the presence of cues prior to method implementation and probes during the assessment, two strategies that were done in the majority of the reviewed interviews, may increase reliability given by individual dietary reports (Smith, 1991; Smith et al., 1991; Thompson and Byers, 1994; Wirfalt, 1998). This was one of the reasons why experts in the area were selected to duly perform the analysis of dietary intake. However, not all studies across different countries could guarantee the collection of data by an expert, probably due to availability of these professionals. Another review, carried out in Africa, also pointed out this limitation (Pisa et al., 2014), referring that in some African countries there is a lack of well-trained nutritionists and dieticians, which makes it challenging, perhaps compromising, the transfer of knowledge and training of interviewers.

The Automated Multiple Pass Method (AMPM), cited by some authors as the reference tool to apply the $24 \mathrm{hR}$, has been tested in different types of populations (Johnson et al., 1996; Jonnalagadda et al., 2000; Conway et al., 2003; Conway et al., 2004) and it has been used in the continuing National Health and Nutrition Examination Survey (NHANES). A single day does not represent the usual consumption because of day-today variation and for that reason several studies conducted multiple recalls. The more recalls are conducted, the greater similitude to usual consumption is obtained and, consequently, better accuracy is achieved. According to Thompson and Byers (1994), the $24 \mathrm{hR}$ and the WR, usually done multiple times, estimate with quantitative accuracy daily food and nutrients intake, while frequency methods, such as FFQ, are limited by their lack of quantitative accuracy. In the reviewed studies, when multiple recalls were applied, they were distributed in non-consecutive days, in order to include week-days and weekend. Ideally all the 7 days of the week should be assessed in order to better represent usual consumption and to avoid possible systematic differences on dietary intake in different days of the week (Willet, 1998). However, the chosen number of days should be considered and decided considering the size of the sample, the purpose of the study, the accuracy desired, the monotony or variety of the diet, as well as the variability of nutrients and foods being assessed (Willet, 1998). Yunsheng and colleagues (Ma et al., 2009) studied how many $24 \mathrm{hR}$ are required to describe an individual's intake and they concluded that three is the sufficient number of recalls, since with less than three significant differences in energy estimation were observed and with more than three this parameter did not significantly improve. In some cases there was no possibility of conducting a multiple recall. According to the perception of some authors, the monotony of the diet (Steyn et al., 2011; Nyuar et al., 2012) or the large number of respondents (Kamau-Mbuthia and Elmadfa, 2007) meant that a single recall was enough. In other cases the lack of time and other resources, such as labour and finances were the main causes (Wiig and Smith, 2007; Maruapula and Chapman-Novakofski, 2008).

Validity of the $24 \mathrm{hR}$ is usually done by comparison between the reports of the respondents in the recall and the measures recorded or weighed by trained and expert observers. An experiment carried out in Ethiopia (Alemayehu et al., 2011) concluded that in the evaluated setting the $24 \mathrm{hR}$ was not an accurate substitute of WR. They concluded that the lack of agreement regarding the number and type of foods between the two methods, caused by memory lapses, and inaccuracies in portion size estimation were the main sources of error. Nevertheless, Gewa et al. (2008) used a to a similar comparison and got different conclusions, supported by higher values of agreement coefficients. In this case, $24 \mathrm{hR}$ could be an acceptable alternative to weighing method, however they considered that it was necessary to improve the recall procedure.

Twenty-four hours recall does not cause a huge burden to the respondents as the food records do. Besides, the recall is less likely to modify eating behavior of the respondents, because it is implemented after they have eaten and it does not require literacy, which is necessary to perform a correct, informative and complete food record. In the studied populations this was the major strength of the $24 \mathrm{hR}$ and a common reason cited by authors for choosing the recalls rather than the food records. Notwithstanding, when compared with frequency methods these two methods have weaknesses in common, since they are not likely to represent the usual consumption of individuals as reflected in frequency methods.

Therefore, FFQ gives a better idea about the usual consumption because the retrospective period is larger. This period could be since the preceding seven days to the preceding year, for instance. The decision about the ideal time frame is related with two issues, the metabolism of the dietary factor being studied and the physiology/pathophysiology of the outcome (Willet, 1998). If the preceding year is used as time frame the researchers assess the dietary intake throughout the whole year, covering both seasons usually referred as dry season and harvest season. When the reference time frame is shorter, the effect of seasonality is not considered, which was a limitation mentioned by several authors. Nevertheless, some of them 
mentioned that seasonality probably does not induce major dietary modifications, even though seasonality is believed to have significant effects on the diet and nutritional status. In the context of Africa, especially in rural areas, seasonality is in fact an important issue since the production and consequent consumption of some foods, such as fruit, vegetables and cereals, are directly affected by weather conditions that characterize both dry and wet seasons (Savy et al., 2006; Asombang et al., 2013; Msaki and Hendriks, 2014). These diet modifications can lead to different intake in some nutrients such as vitamins and fat (Faber and Laubscher, 2008; Mitchikpe et al., 2008; Wiesmann et al., 2009; Masibo, 2013). More than half of the studies that used FFQ as dietary assessment tool did not specify FFQ's time frame, although the preceding year was the most cited.

Some of the FFQ utilized by the reviewed authors were specifically created for those studies, hence they included the elaboration of the food list besides other steps. Regarding the food list, the way of organizing food items in a questionnaire determines the answer of the respondent. Wirfalt (1998) cited some studies that had better results regarding reproducibility and validity when food items were organized according to the type of meals they usually consumed rather than when they were organized according to food groups. Most of the reviewed studies that used FFQ organized their dietary information in terms of food groups.

As it is possible to observe from the results section, among the studies developed in other countries besides South Africa, few of them used FFQ as one of the selected tools. In these studies authors had to create a new FFQ because in countries such as Kenya, Mozambique, Uganda, Tanzania, Botswana, Morocco or Ethiopia there is no population-specific FFQ. This shows the need for developing new food frequency tools within the majority of African countries.

Validity of a FFQ is not a very practical and easy process to perform, because it requires a noninvasive observation of total diet of the respondents during a long period, and these validation studies have not yet been done (Thompson and Byers, 1994). What is currently and usually done is the comparison of results from FFQ with that from recalls and records (Thompson and Byers, 1994), a process which for some authors should be called calibration instead of validation (Willet, 1998).

Some of the presented studies were also tested for reproducibility. The previous referred THUSA questionnaire was tested for reproducibility by other authors (Wentzel-Viljoen et al., 2011) in a different population, with Seatswana-speaking adults. They concluded that this questionnaire was reproducible.

Besides these reported cases there is still a lack of validated methods for use in a specific population, and thus the need of updating the validated dietary assessment methods across African countries is emergent. When a validation study is performed, researchers have more confidence in their method since it means that it can actually measure the aspects of diet that it was designed for (Willet, 1998), as long as the study is well-performed.

\section{Estimation of food portion size}

Estimation of foods portion size is one of the challenging aspects of the recall tools (Thompson and Byers, 1994; Willet, 1998; Venter et al., 2000). In several households within rural settings it is common that all the family eat from a shared bowl, hampering the estimation process (Hudson, 1995; Huybregts et al., 2008; Pisa et al., 2014). There are visual aids which are used to help respondents to accurately report the amounts of food items consumed. In the reviewed studies several tools were used, such as household measures, food models (two-dimension or three-dimension), food photographs and pictures, containers, real food items, among others. Within the studies that used $24 \mathrm{hR}$, some did not mention how this estimation was done leaving less margin to evaluate the associated effectiveness (Mostert et al., 2005; Mounir et al., 2007; O'Keefe et al., 2007; Maruapula and Chapman-Novakofski, 2008; Oldewage-Theron et al., 2008; Heimburger et al., 2010; Gibson et al., 2011; López et al., 2012; Pereko et al., 2012; Changamire et al., 2014; May et al., 2014). In fact, there is little data concerning the accuracy of portion size estimation tools. A study of Byrd-Bredbenner and Schwartz (2004) evaluated if using portion size measurement aids (PSMAs) had effect on portion size estimation accuracy, in a group of young adults. The PSMAs were two: one was a life-size card containing pictures of both tennis and golf balls and the other one were both real tennis and golf balls. They concluded that even if the estimation accuracy was improved by the use of PSMAs, estimation errors still remain. In Burkina Faso an album of food photographs was validated for use on food portion size estimation of frequently consumed food items (Huybregts et al., 2008). This validated album, with four photos per one of the eight evaluated food items, could be used in $24 \mathrm{hR}$ as a valuable and accurate tool in West African rural settings. Another example of advances in this area is the book of food photographs developed and tested by Venter et al. (2000), with the purpose to be used in the THUSA study. A more recent work (Lombard et al., 2013), also carried out in rural areas of South Africa, focused on the development of a food photography series, mainly geared toward oesophageal cancer patients.

In FFQs, portion size of the food items may either be or not be assessed; in this latter option it can be assumed a common portion size for all subjects. There were few papers among the many reviewed in which authors, having collected the amounts consumed by the respondents, did not report how it was done (Belgnaoui and Belahsen, 2006; Jackson et al., 2007; Vorster et al., 2007; Tessier et al., 2008; Delport et al., 2011; Baroudi et al., 2014; Botha et al., 2014). The most used tools to estimate portion size were household measures, food models (two-dimension or three-dimension) and food photographs, including the validated food photo manual (Venter et al., 2000). Implementation of the FFQ by mail or by telephone was not used in the reviewed studies. Although these possibilities are considered or applied many times in European or American dietary surveys, the socio-economical, political or geophysical conditions found in many African countries may entail natural communication barriers. 


\section{Food composition databases}

To convert the dietary intake into nutrient intake some components are needed, such as a food composition database, a coding system for matching foods listed with the entries in the food composition database and a software for calculating the nutrients' composition (Thompson and Byers, 1994; Willet, 1998). The right choice of the nutrient database is very important because the estimation of nutrient intake is affected by it. Parameters such as the completeness regarding the included food items and evaluated nutrients are related to the constant updating of the database, so it is imperative to support the analysis on the most recent updated version available (Thompson and Byers, 1994). These nutrient databases are commonly included in computer software programs that process data and calculate individual dietary intake. The choice of the software should be based on the level of specification and detail needed, on the type of foods that are usually consumed by the studied population and on the hardware and software requirements. As mentioned above, and also noted by other reviews (Ngo et al., 2009; Ochola and Masibo, 2014; Pisa et al., 2014), there are few African countries with their own FCT, and countries without their own food table need to use either FCTs from neighboring countries or FAO's FCTs, which decreases reliability of the results. This was one of the most cited limitations by the authors. In this review several softwares were mentioned by the authors, however most of them are composed by the same FCTs, which makes imperative the need of creating updated tools. An example of an effort to improve this lack of countryspecific databases is the study of Becquey et al. (2009), who developed a FCT for Burkina Faso bringing together the information of three sources, namely the FCT for Mali, supplemented by the WorldFood FCT for Senegal and the USDA database. This table was complete for energy, macronutrients and eleven micronutrients. The variability within the same continent is huge, and different lifestyles and typical food patterns are found even within the same country, which makes the finding of uniformity in the FCTs quite challenging, and eventually impossible, and so the countries find themselves obliged to create their own tools. In order to fight against the current lack of updating of these tools it is necessary to join forces geared towards the development of both new and countryspecific FCTs or at least to complete the existing ones.

Besides the limitations that were mentioned along this discussion, limitations related to the adopted methodologies, to self-reporting, to small size sample were also cited. Furthermore, the traditional way of cooking is another challenging question too, because household's women resort to memory and taste rather than follow standard recipes or measurements to cook their dishes, which may hamper a reliable assessment (Wojtusiak et al., 2011).

Concerning improvements in developed countries according to new-technology based dietary assessment methods, it is envisaged that, in the coming years, these innovative tools could be used in African countries. Examples of these methods are a mobile device food record (Zhu et al., 2008) and a system based on images of foods (Schap et al., 2014). Although Wojtusiak and colleagues (Wojtusiak et al., 2011) defend that some methods based on automated analysis of photos, voice recognition and use of simple graphical symbols representing food could be applied in dietary assessment in African countries, there is still a long way to go before that may become a reality. Africa is comprised by a large part of rural areas, some of which even do not have sanitation or electricity and food insecurity is one of the major problems. Africa has a particular social organization characterized by the co-existence of several ethnic groups and societies each one with its own traditions and habits, hampering its conjoint growth and balanced development.

\section{Conclusions and recommendations}

Globally, African countries are crossing a challenging public health crisis, which coupled to both weak and poor social and governmental structure leads to major concerns related to health, food security and socio-economic issues. Aiming to counteract the double health burden, characterized by both communicable and non-communicable diseases, a major effort is emerging toward development of health policies and the planning, development and evaluation of nutritional interventional programs.

Data obtained from this review provided a better knowledge of the research works that have been developed in African countries concerning food habits of individuals, strengthening the need to apply a bigger effort in these many nations. As shown in this review, in African countries, there is a lack of periodical, accurate, reliable and country-specific methodologies to assess dietary intake in adults. Major limitations on dietary assessment in Africa were, on the one hand, the deficiency in validated and standardized methodologies to perform the dietary assessment and, on the other, the usage of countryunspecific food composition databases. So, related to the first it is necessary to proceed with validation studies and test for reliability of the used methods, in order to assure the consistency and accuracy of measurements, as well as the confidence therein. Regarding the second cited limitation there is an emergent need to improve the already existing databases by updating food data and to develop suitable country-specific ones for those countries that don't have their own food composition table.

Countries with better social, financial and health resources evidenced more activity in this field and performed more investigations, providing greater data availability. Due to distinct social organization of the continent, with major problems, such as high rates of inadequate education, illiteracy, food insecurity and a frail global health system, the work on this field should be continued and widened to include other African countries. Once surpassed some of these basic challenges it will be desired to follow developed countries' trends in what concerns the usage of innovative tools.

\section{ORCID}

Catarina Vila-Real (iD http://orcid.org/0000-0002-1352-6525

\section{References}

Abebe, Y. et al. (2008). Inadequate intakes of dietary zinc among pregnant women from subsistence households in Sidama, Southern Ethiopia. Pub. Health Nutr. 11:379-386. 
Addo, A. et al. (2011). Food insecurity and perceived stress but not HIV infection are independently associated with lower energy intakes among lactating Ghanaian women. Maten. Child Nutr. 7:80-91.

Alaofe, H. et al. (2009). Education and improved iron intakes for treatment of mild iron-deficiency anemia in adolescent girls in southern Benin. Food Nutr. Bull. 30:24-36.

Alemayehu, A., Abebe, Y. and Gibson, R. S. (2011). A 24-h recall does not provide a valid estimate of absolute nutrient intakes for rural women in southern Ethiopia. Nutrition. 27:919-924.

Amare, B. et al. (2012). Nutritional status and dietary intake of urban residents in Gondar, Northwest Ethiopia. BMC Pub. Health. 12:752.

Anderson, S. G. et al. (2011). Nutrient intakes and dysglycaemia in populations of West African origin. Br. J Nutr. 105:297-306.

Aounallah-Skhiri, H. et al. (2011). Nutrition transition among adolescents of a south-Mediterranean country: Dietary patterns, association with socio-economic factors, overweight and blood pressure. A cross-sectional study in Tunisia. Nutr J. 10:38.

Asombang, A. W. et al. (2013). Gastric cancer in Zambian adults: A prospective case-control study that assessed dietary intake and antioxidant status by using urinary isoprostane excretion. Am. J. Clin. Nutr.. 97:1029-1035.

El Ati, J. et al. (2004). Food Frequency Questionnaire for Tunisian dietary intakes: Development, reproducibility and validity. Ar. J. Food Nutr.. 5:10-30.

Baroudi, O. et al. (2014). Impact of lifestyle factors and nutrients intake on occurrence of gastrointestinal cancer in Tunisian population. Tumor Bio. 35:5815-5822.

Baroudi, T. et al. (2010). Dietary intakes of essential nutrients among Arab and Berber ethnic groups on rural Tunisian island. Nutrition. 26:75-81.

Becquey, E., Capon, G. and Martin-Prével, Y. (2009). Dietary diversity as a measure of the micronutrient adequacy of women's diets: Results from Ouagadougou Burkina Faso Site. Food and Nutrition Technical Assistance. Technical Report.

Becquey, E. and Martin-Prevel, Y. (2010). Micronutrient adequacy of women's diet in Urban Burkina Faso is low. J. Nutr. 140:2079S-2085S.

Belgnaoui, S. and Belahsen, R. (2006). Nutrient intake and food consumption among pregnant women from an agricultural region of Morocco. Int. J. Food Sci. Nutr. 57:19-27.

Botha, S. et al. (2014). Associations of suPAR with lifestyle and cardiometabolic risk factors. Eur. J. Clin. Invest. 44:619-626.

Boumaiza, I. et al. (2012). Relationship between Leptin G2548A and Leptin Receptor Q223R gene polymorphisms and obesity and metabolic syndrome risk in Tunisian volunteers. Gene. Testing Mole. Biomar. 16:726-733

Boutayeb, A. (2006). The double burden of communicable and non-communicable diseases in developing countries. Trans. Roy. Soc. Trop. Med. Hyg. 100:191-199.

Bunch S., Murphy, S. (1997). WorldFood Dietary Assessment System. Available at: http://www.fao.org/infoods/infoods/software-tools/en/

Byrd-Bredbenner, C. and Schwartz, J. (2004). The effect of practical portion size measurement aids on the accuracy of portion size estimates made by young adults. J. Hum. Nutr. Diet. 17:351-357.

Changamire, F. T. et al. (2014). Macronutrient and sociodemographic determinants of gestational weight gain among HIV-negative women in Tanzania. Food Nutr. Bull. 35:43-50.

Charlton, K. E., Kolbe-Alexander, T. L. and Nel, J. H. (2005). Micronutrient dilution associated with added sugar intake in elderly black South African women. Eur. J. Clin. Nutr. 59:1030-1042.

Conway, J., Ingwersen, L. and Moshfegh, A. (2003). Effectiveness of the USDA 5-step multiple-pass method to assess food intake in obese and non-obese women. Am. J. Clin. Nutr. 77:71-78.

Conway, J. M., Ingwersen, L. A. and Moshfegh, A. J. (2004). Accuracy of dietary recall using the USDA five-step multiple-pass method in men: An observational validation study. J. Am. Diet. Ass. 104:595-603.

CyberSoft, I. (1986). NutriBase Professional Nutrition and Fitness Software Site. Available at: http://www.nutribase.com/.

Dapi, L. N. et al. (2010). Energy and nutrient intakes in relation to sex and socio-economic status among school adolescents in urban Cameroon, Africa. Public Health Nutr 14:904-913.
Davison, S. and Mandible, D. (1994). The Food Processor Plus 6.02. Available at: http://www.esha.com/products/food-processor/.

Decarli, A. et al. (1996). Validation of a food-frequency questionnaire dietary intakes in cancer studies in Italy. AEP. 6:110-118.

Delport, R. et al. (2011). Changes in retinol-binding protein concentrations and thyroid homeostasis with nonoccupational exposure to DDT. Environ. Health Persect. 119:647-651.

Erhardt, J. and Gross, R. (2007). NutriSurvey. Available at: http://www. nutrisurvey.de/.

Faber, M. and Kruger, S. (2005). Dietary intake, perceptions regarding body weight, and attitudes toward weight control of normal weight, overweight, and obese black females. Ethnicity. 15:238-245.

Faber, M. and Laubscher, R. (2008). Seasonal availability and dietary intake of beta-carotene-rich vegetables and fruit of 2-year-old to 5-year-old children in a rural South African setting growing these crops at household level. Int. J. Food Sci. Nutr. 59:46-60.

Fletcher, L. (1994). Microdiet. Available at: http://www.microdiet.co.uk/.

Franceschi, S. et al. (1993). Reproducibility of an Italian food frequency questionnaire for cancer studies: results for specific food items. Eur. J. Cancer. 29A:2298-2305.

Gewa, C., Murphy, S. P. and Neumann, C. G. (2008). A comparison of weighed and recalled intakes for schoolchildren and mothers in rural Kenya. Publ. Health Nutr. 12:1197-1204.

Gibson, R. S. et al. (2011). Plasma selenium concentrations in pregnant women in two countries with contrasting soil selenium levels. J. Trace Elem. Med. Biol. 25:230-235.

Gibson, R. S. (2005). Principles of Nutrition Assessment. 2nd ed. Oxford University Press, New York.

Gibson, R. S. et al. (2008). Zinc, Gravida, infection, and iron, but nor vitamin B-12 or folate status, predict hemoglobin during pregnancy in Southern Ethiopia. J. Nutr. 138:581-586.

Gibson, R. S. and Ferguson, E. L. (1999). An Interactive 24-Hour Recall for Assessing the Adequacy of Iron and Zinc Intakes in Developing Countries. International Life Science Institute Press, Washington DC.

Godin, G. (2007). CANDAT. Available at: http://www.foodresearch.ca/.

Goedecke, J. H. et al. (2009). Differential effects of abdominal adipose tissue distribution on insulin sensitivity in black and white South African women. Obe. (Silver Spring, Md.). 17:1506-1512.

Gouveia de Oliveira, A. (2009). Bioestatística, Epidemiologia e Investigação: Teoria e Aplicações Lidel, Lisboa.

Grant, K., Langenhoven, M. and Stockton, M. (1992). Foodfinder dietary analysis software. Available at: http://safoods.mrc.ac.za/Foodfinder DEMO.pdf.

Haileslassie, K., Mulugeta, A. and Girma, M. (2013). Feeding practices, nutritional status and associated factors of lactating women in Samre Woreda, South Eastern Zone of Tigray, Ethiopia. Nutr. J. 12:28.

Hansen, A. W. et al. (2011). Dietary patterns, food and macronutrient intakes among adults in three ethnic groups in rural Kenya. Pub. Health Nutr. 14:1671-1679.

Haregu, T. N. et al. (2014). National responses to HIV / AIDS and noncommunicable diseases in developing countries: Analysis of strategic parallels and differences. J. Pub. Health Res. 3:25-42.

Hattingh, Z. et al. (2006). Macronutrient intake of HIV-seropositive women in Mangaung, South Africa. Nutr. Res. 26:53-58.

Heimburger, D. C. et al. (2010). Serum phosphate predicts early mortality in adults starting antiretroviral therapy in Lusaka, Zambia: A prospective cohort study. PLoS ONE. 5:1-7.

Hogenkamp, P. S. et al. (2008). Association between consumption of black tea and iron status in adult Africans in the North West Province: The THUSA study. Br. J. Nutr. 100:430-437.

Hudson, G. J. (1995). Food intake in a West African village. Estimation of food intake from a shared bowl. Br. J. Nutr. 73:551-569.

Huybregts, L. et al. (2008). Validity of photographs for food portion estimation in a rural West African setting. Pub. Health Nutr. 11:581-587.

Huybregts, L. F. et al. (2009). Dietary behaviour, food and nutrient intake of pregnant women in a rural community in Burkina Faso. Mater. Child Nutr. 5:211-222.

Ijarotimi, O. S. and Keshinro, O. O. (2008). Nutritional knowledge, nutrients intake and nutritional status of hypertensive patients in Ondo State, Nigeria. Tanz. J. Health Res. 10:59-67. 
Iowa State University. (1996). A user's guide to C-Side: software for intake distribution estimation. Available at: http://www.card.iastate.edu/publi cations/synopsis.aspx?id $=168$.

Irvine, S. L., Hummelen, R. and Hekmat, S. (2011). Probiotic yogurt consumption may improve gastrointestinal symptoms, productivity, and nutritional intake of people living with human immunodeficiency virus in Mwanza, Tanzania. Nutr. Res. 31:875-881.

Islam, S. et al. (2014). Non Communicable Diseases (NCDs) in developing countries: A symposium report. Glob. Health. 10.

Jackson, M. et al. (2007). Diet and overweight and obesity in populations of African origin: Cameroon, Jamaica and the UK. Pub. Health Nutr. 10:122-130.

Jackson, M. D. et al. (2012). Validation and reproducibility of an FFQ for use among adults in Botswana. Pub. Health Nutr. 16:1995-2004.

Joffe, Y. T. et al. (2011). The $-308 \mathrm{G} / \mathrm{A}$ polymorphism of the tumour necrosis factor- $\alpha$ gene modifies the association between saturated fat intake and serum total cholesterol levels in white South African women. Gen. Nutr. 6:353-359.

Joffe, Y. T. et al. (2012). The tumor necrosis factor- $\alpha$ gene $-238 \mathrm{G}>\mathrm{A}$ polymorphism, dietary fat intake, obesity risk and serum lipid concentrations in black and white South African women. Eur. J. Clin. Nutr. 66:1295-1302.

Joffe, Y. T. et al. (2010). Tumor necrosis factor-a gene -308 G / A polymorphism modulates the relationship between dietary fat intake, serum lipids, and obesity risk in black South African women 1, 2. J. Nutr. 901-907.

Johnson, R. K., Driscoll, P. and Goran, M. I. (1996). Comparison of multiple-pass 24-hour recall estimates of energy intake with total energy expenditure determined by the doubly labeled water method in young children. J. Am. Diet. Assoc. 96:1140-1144.

Jonnalagadda, S. S. et al. (2000). Accuracy of energy intake data estimated by a multiple-pass, 24-hour dietary recall technique. J. Am. Diet. Assoc. 100:303-311.

Jordan, I. et al. (2013). Dietary patterns and breast cancer risk among women in northern Tanzania: A case-control study. Eur. J. Nutr. 52:905-915.

Kamau-Mbuthia, E. and Elmadfa, I. (2007). Diet quality of pregnant women attending an antenatal clinic in Nakuru, Kenya. Ann. Nutr. Meta. 51:324-330.

Kennedy, G., Fanou, N. and Brouwer, I. D. (2009). Dietary diversity as a measure of the micronutrient adequacy of women's diets: Results from Bamako, Mali Site. Food And Nutrition Technical Assistance, Technical Report.

Kesa, H. and Oldewage-Theron, W. (2005). Anthropometric indications and nutritional intake of women in the Vaal Triangle, South Africa. Pub. Health. 119:294-300.

Kim, F. et al. (2014). Deficiencies of macronutrient intake among HIVpositive breastfeeding women in Dar es Salaam, Tanzania. 67:569-572.

Koethe, J. R. et al. (2013). Self-reported dietary intake and appetite predict early treatment outcome among low body mass index adults initiating HIV treatment in sub-Saharan Africa. Pub. Health Nutr. 16:549-558.

Kolahdooz, F., Spearing, K. and Sharma, S. (2013). Dietary adequacies among South African adults in Rural KwaZulu-Natal. PLoS ONE. 8:1-6.

Korkalo, L. et al. (2014). A cross-sectional study on the diet and nutritional status of adolescent girls in zambia province, mozambique (the zane study): Design, methods, and population characteristics. J. Med. Inter. Res. 16:1-13.

Kruger, A. et al. (2012). Sex differences independent of other psycho-sociodemographic factors as a predictor of body mass index in black South African adults. J.Health, Popu. Nutr. 30:56-65.

Kruger, A., Lekalakalamokgela, S. E. and Wentzel-Viljoen, E. (2011). Rural and urban older African caregivers coping with HIV/AIDS are nutritionally compromised. J. Nutr. Geronto. Geri. 30:274-290.

Lamri-Senhadji, M. Y. et al. (2009). Assessment of dietary consumption and time-course of changes in serum lipids and lipoproteins before, during and after Ramadan in young Algerian adults. Singapore Medi. J. 50:288-294.

Lombard, M. et al. (2013). A Food photograph series for identifying portion sizes of culturally specific dishes in rural areas with high incidence of oesophageal cancer. Nutrients. 5:3118-3130.
López, P. M. et al. (2012). Nutritional status of adolescents in the context of the Moroccan nutritional transition: The role of parental education. $J$. Bioso. Sci. 44:481-494.

Luke, A. et al. (2011). Protocol for the modeling the epidemiologic transition study: A longitudinal observational study of energy balance and change in body weight, diabetes and cardiovascular disease risk. BMC Pub. Health. 11:927.

Lukmanji, Z. et al. (2013). Dietary patterns, nutrient intake, and sociodemographic characteristics in HIV-infected Tanzanian pregnant women. Eco. Food Nutr. 52:34-62.

$\mathrm{Ma}, \mathrm{Y}$. et al. (2009). Number of 24-hour diet recalls neede to estimate energy intake. Ann. Epidemiol. 19:553-559.

MacIntyre, U. E., Venter, C. S. and Vorster, H. H. (2001a). A culture-sensitive quantitative food frequency questionnaire used in an African population: 1. development and reproducibility. Pub. Health Nutr. 4:53-62.

MacIntyre, U. E., Venter, C. S. and Vorster, H. H. (2001b). A culture-sensitive quantitative food frequency questionnaire used in an African population: 2. Relative validation by 7-day weighted records and biomarkers. Pub. Health Nutr.. 4:63-71.

MacKeown, J. M., Pedro, T. M. and Norris, S. (2007). Energy, macro- and micronutrient intake among a true longitudinal group of South African adolescents at two interceptions (2000 and 2003): the Birth-to-Twenty (Bt20) study. Pub. Health Nutr. 10:635-643.

Mala, J., Tuitoek P. J. and Odhiambo R. A. (2012). Effect of dietary intakes on pregnancy outcomes: A comparative study among HIV-infected and uninfected women at Nyanza Provincial General Hospital, Kenya. Afr. J. Food, Agric. Nutr. Dev. 12:6776-6793.

Maruapula, S. D. and Chapman-Novakofski, K. M. (2008). Poor intake of milk, vegetables, and fruit with limited dIetary variety y Botswana's elderly. J. Nutr. Elderly. 25:3-22.

Masibo, P. K. (2013). Effects of Initial Nutritional Status on the Responses to a School Feeding Programme among School Children Aged 6 to 13 Years in the Millennium Villages Project, Siaya, Kenya. Dissertation presented for the degree of Doctor of Philosophy (Nutritional Sciences) in the Faculty of Medicine and Health Sciences at Stellenbosch University Supervisor: Stellenbosch University.

May, P. a. et al. (2014). Dietary intake, nutrition, and fetal alcohol spectrum disorders in the Western Cape Province of South Africa. Reprod. Toxico. (Elmsford, N.Y.). 46C:31-39.

Mbochi, R. W. et al. (2012). Predictors of overweight and obesity in adult women in Nairobi Province, Kenya. BMC Pub. Health. 12:823.

Merchant, A. T. et al. (2005). Nutrient estimation from an FFQ developed for a Black Zimbabwean population. Nutr. J. 4:37.

Mitchikpe, C. E. S. et al. (2008). Seasonal variation in food pattern but not in energy and nutrient intakes of rural Beninese school-aged children. Pub. Health Nutr. 12:414-422.

Mostert, D. et al. (2005). Dietary intake of pregnant women and their infants in a poor black South African community. Curationis. 28:1219.

Mounir, G. M. et al. (2007). Nutritional factors affecting the menarcheal state of adolescent school girls in Alexandria. J. Egyp. Pub. Health Asso. 82:239-260

Msaki, M. M. and Hendriks, S. L. (2014). Measuring household food security using food intake indicators in rural Kwazulu. Eco. Food Nutr. 53:193-213.

Mupere, E. et al. (2012). Low nutrient intake among adult women and patients with severe tuberculosis disease in Uganda: a cross-sectional study. BMC Pub. Health. 12:1050-1050.

Nago, E. S. et al. (2010). Food, energy and macronutrient contribution of out-of-home foods in school-going adolescents in Cotonou, Benin. $\mathrm{Br}$. J. Nutr. 103:281-288.

Namugumya, B. S. and Muyanja, C. (2011). Contribution of street foods to the dietary needs of street food vendors in Kampala, Jinja and Masaka districts, Uganda. Pub. Health Nutr. 15:1503-1511.

Naude, C. E. et al. (2011). Growth and weight status in treatment-naïve 12-16 year old adolescents with alcohol use disorders in Cape Town, South Africa. Nutr. J. 10:87.

Ngo, J. et al. (2009). How dietary intake methodology is adapted for use in European immigrant population groups - a review. Br. J. Nutr. 101 (Suppl):S86-S94. 
Ngosom J. and Abono, A. (1989). Les resources alimentaires du Cameroun: Répartition Ecologique, classification et valeur nutritive (The Food Resources of Cameroon: Ecological Distribution, Classification and Nutritional Value). Yaoundé: Institut de Recherche Médicinale et d'études de plantes médicinales.

Nutrition Coordinating Center's University of Minnesota, Nutrition Data System for Research. Available at: www.ncc.umn.edu.

Nyuar, K. B., Khalil, A. K. H. and Crawford, M. A. (2012). Dietary intake of sudanese women: a comparative assessment of nutrient intake of displaced and non-displaced women. Nutr. Health. 21:131-44.

O'Keefe, S. J. D. et al. (2007). Why do African Americans get more colon cancer than Native Africans? J. Nutr. 137:175S-182S.

Ochola, S. and Masibo, P. K. (2014). Dietary intake of schoolchildren and adolescents in developing countries. Ann. Nutr. Meta. 64:2440.

Oguntibeju, O. O., Van der Heever, W. M. J. and Van Schalkwyk, F. E. (2007). The interplay between socio-demographic variables, nutritional and immune status of HIV-positive/AIDS patients. Pak. J. Bio. Sci. 10:3592-3598.

Olayiwola, I. O. et al. (2012). Serum micronutrient status and nutrient intake of elderly Yoruba people in a slum of Ibadan, Nigeria. Pub Health Nutr. 17:455-461.

Oldewage-Theron, W. et al. (2008). Anaemia prevalence and dietary intake of elderly persons living in a peri-urban settlement in South Africa. $J$. Fam. Eco. Cons. Sci./Tydskrif vir Gesinsekologie en Verbruikerswetenskappe. 36:22-29.

Oldewage-Theron, W. et al. (2008). Health status of an elderly population in Sharpeville, South Africa. Health SA Gesondheid, 13:3-17.

Oldewage-Theron, W. and Kruger, R. (2011). Dietary diversity and adequacy of women caregivers in a peri-urban informal settlement in South Africa. Nutrition. 27:420-427.

Oldewage-theron, W. H. et al. (2005). Situation analysis of an informal settlement in the Vaal Triangle. Dev. S. Afr. 22:13-26.

Oldewage-Theron, W. H., Dicks, E. G. and Napier, C. E. (2006). Poverty, household food insecurity and nutrition: Coping strategies in an informal settlement in the Vaal Triangle, South Africa. Pub. Health. 120:795-804.

Oldewage-Theron, W. H., Kruger, R. and Egal, A. A. (2014). Socio-economic variables and nutrient adequacy of women in the Vaal region of South Africa. Eco. Food Nutr. 53:514-527.

Oldewage-Theron, W. H., Samuel, F. O. and Djoulde, R. D. (2010). Serum concentration and dietary intake of vitamins $\mathrm{A}$ and $\mathrm{E}$ in low-income South African elderly. Clin. Nutr. 29:119-123.

Oldewage-Theron, W. H., Samuel, F. O. and Venter, C. S. (2008). Zinc deficiency among the elderly attending a care centre in Sharpeville, South Africa. J. Human Nutr. Diet. 21:566-574.

Ortega, R. M. et al. (2008). DIAL 1.0: Programa para evaluación de dietas y gestión de datos de alimentación. Available at: http://www.alceingenieria.net.

Papathakis, P. C. and Pearson, K. E. (2012). Food fortification improves the intake of all fortified nutrients, but fails to meet the estimated dietary requirements for vitamins A and B6, riboflavin and zinc, in lactating South African women. Pub. Health Nutr. 15:1810-1817.

Pereko, K. K. et al. (2012). Overnutrition and associated factors among adults aged 20 years and above in fishing communities in the urban Cape Coast Metropolis, Ghana. Pub. Health Nutr. 16:1-5.

Pirone, C. et al. (1993). Nutridata Nutrition Services For The Food Industry. Available at: www.nutridata.com.

Pisa, P. et al. (2012). Social drift of cardiovascular disease risk factors in Africans from the North West Province of South Africa : the PURE study: Cardiovascular topics. Cardiovas. J. Afr. 23:371-378.

Pisa, P. T. et al. (2014). Inventory on the dietary assessment tools available and needed in Africa: A prerequisite for setting up a common methodological research infrastructure for nutritional surveillance, research and prevention of diet-related non-communicable diseases. Cri. Rev. Food Sci. Nutr. DOI:1080/10408398.2014.981630.

Powell, B. et al. (2013). Wild foods from farm and forest in the East Usambara Mountains, Tanzania. Eco. Food Nutr. 52:451-78.

Pretorius, S. et al. (2012). Feeding the emergence of advanced heart disease in Soweto: A nutritional survey of black African patients with heart failure. Cardiovas. J. Afr. 23:245-251.
Rankin, D. et al. (2011). Dietary intakes assessed by 24 -h recalls in periurban African adolescents: Validity of energy intake compared with estimated energy expenditure. Eur. J. Clin. Nutr. 65:910-919.

Richter, L. et al. (2007). Cohort Profile: Mandela's children: The 1990 birth to twenty study in South Africa. J Epidemiol. 36:504-511.

Sas, N. (2007). NutriLog Nutrition Software for Professionals. Available at: www.nutrilog.com.

Savy, M. et al. (2006). Dietary diversity scores and nutritional status of women change during the seasonal food shortage in rural Burkina Faso. J. Nutr. 136:2625-2632.

Scarcella, P. et al. (2011). The impact of integrating food supplementation, nutritional education and HAART (Highly Active Antiretroviral Therapy) on the Nutritional Status of Patients living with HIV / AIDS in Mozambique: Results from the DREAM Programme. Igiene e Sanita Pubblica - Parte Scientifica e Pratica. 67:41-53.

Schap, T. E. et al. (2014). Merging dietary assessment with the adolescent lifestyle. J. Human Nutr. Diet. 27(Suppl.1):82-88.

Sehmi, J. (1993). National food composition tables and the planning of satisfactory diets in Kenya. 200 pgs. Government Printers, Nairobi.

Sharma, S. et al. (1996). Development of food frequency questionnaires in three population samples of African origin from Cameroon, Jamaica and Caribbean migrants to the UK. Eur. J. Clin. Nutr. 50:479-486.

Sheehy, T. et al. (2013). Development of a quantitative food frequency questionnaire for use among rural South Africans in KwaZulu-Natal. J. Human Nutr. Diet. 27:443-449.

Smith, A. F. (1991). Cognitive processes in long-term dietary recall. Vital Center for Health Statistics. In: Vital Center for Healh Statistics. 6:4.

Smith, A. F., Jobe, J. B. and Mingay, D. J. (1991). Retrieval from memory of dietary information. App. Cogn. Psyc. 5:269-296.

Sodjinou, R. et al. (2009). Dietary patterns of urban adults in Benin: Relationship with overall diet quality and socio-demographic characteristics. Eur. J. Clin. Nutr. 63:222-228.

Sodjinou, R. et al. (2008). Obesity and cardio-metabolic risk factors in urban adults of Benin: Relationship with socio-economic status, urbanisation, and lifestyle patterns. BMC Pub. Health. 8:84.

Souci, S. W., Fachmann, W. and Kraut H. (2000). La composition des aliments. Tableaux des valeurs nutritives 6 th edition. Stuttgart: CRC Press \& Medpharm Scientific Publishers.

Steyn, N. and Senekal, M. (2005). A Guide for the Use of the Dietary Assessment and Education Kit (DAEK). Cape Town, South Africa.

Steyn, N. P. et al. (2011). Dietary, social, and environmental determinants of obesity in Kenyan women. Scad. J. Pub. Health. 39:88-97.

Steyn, N. P. et al. (2012). Urbanisation and the nutrition transition: A comparison of diet and weight status of South African and Kenyan women. Scad. J. Pub. Health. 40:229-238.

Steyn, N. P. and Nel, J. H. (2006). Dietary intake of adult women in South Africa and Nigeria with a focus on the use of spreads. South African Medical Research Council, Cape Town.

Tan, S., Wenlock, R. and Buss, D. (1985) Immigrant Foods: Second Supplement to McCance and Widdowson's The Composition of foods London.

Termote, C. et al. (2012). A biodiverse rich environment does not contribute to a better diet: A case study from DR Congo. PLoS ONE. 7:1-10.

Tesfaye, F., Byass, P. and Wall, S. (2008). Concurrent comparison of energy intake and expenditure among adults in Butajira District, Ethiopia. Pub. Health Nutr. 11:675-683.

Tessier, S. et al. (2008). Regular users of supermarkets in Greater Tunis have a slightly improved diet quality. J. Nutr. 138:768-774.

Thompson, F. E. and Byers, T. (1994). Dietary assessment resource manual. J. Nutr. 124:2245S-2317S.

Research Group Food Chemistry and Human Nutrition and Medicine, Universiteit Gent and Nutrition and Child Health Unit of the Institute of Tropical Medicine. (n.a.) Lucille food analysis software. Belgium.

US Department of Agriculture, Agricultural Research Service, N.D.L. (1996). USDA National Nutrient Database for Standard Reference, Release 28.

Venter, C. S., MacIntyre, U. E. and Vorster, H. H. (2000). The development and testing of a food portion photograph book for use in an African population. J. Human Nutr. Diet. 13:205-218. 
de Villiers, A. et al. (2006). Relative Validity of a Quantified Food Frequency Questionnaire in Black South African Women. University of Cape Town.

Vorster, H. H. et al. (2007). Cardiovascular disease risk factors and socioeconomic position of Africans in transition: The THUSA study. Cardiovas. J. Afr. 18:282-289.

Walton, C. et al. (2012). Associations of diet quality with dairy group membership, membership duration and non-membership for Kenyan farm women and children: A comparative study. Pub Health Nutr. 17:1-10

Waudo, J. et al. (2005). Food Consumption Patterns and Nutrient Intake By Women And Under Five Year Old Children In Wetlands Of Lake VIctoria Basin. In: Food \& Nutrition Security for Health and Development. Proceedings of the Inaugural National Nutrition Congress [INNC]. Nairobi, Kenya.

Wentzel-Viljoen, E., Laubscher, R. and Kruger, A. (2011). Using different approaches to assess the reproducibility of a culturally sensitive quantified food frequency questionnaire. South Afri. J. Clin. Nutr. 24:143-148.

Wiesmann, D., Arimond, M. and Loechi, C. (2009). Dietary diversity as a measure of the micronutrient adequacy of women's diets: Results from Rural Mozambique Site. Food And Nutrition Technical Assistance, Technical Report.

Wiig, K. and Smith, C. (2007). An exploratory investigation of dietary intake and weight in human immunodeficiency virus-seropositive individuals in Accra, Ghana. J. Am. Diet. Assoc. 107:1008-1013.

Willet, W. (1998). Nutrition Epidemiology. 2nd ed. Oxford University Press, New York.
Wirfalt, E. (1998). Cognitive aspects of dietary assessment. Sca. J. Nutr. 42:56-59.

Wojtusiak, J., Gewa, C. A. and Pawloski, L. R. (2011). Dietary assessment in Africa: integration with innovative technology. Afr. J.Food, Agri., Nutr. Devel. 11:5629-5645.

Wolmarans, P. and Danster, N. A. (2008). Characteristics of the South African Food Composition Database, an essential tool for the nutrition fraternity in the country: Part I. S Afr J. Clin. Nutr. 21(4):308-313.

World Health Organization. (2011). Global status report on noncommunicable diseases 2010. World Health Organization - Reginal Office for Africa. (2006). The African Regional Health Report: The Health of the People. Available at: http://www.who.int/bulletin/africanhealth/en/.

World Health Organization - Reginal Office for Africa. (2006). The African Regional Health Report: The Health of the People. Available at: http:// www.who.int/bulletin/africanhealth/en/.

Wrottesley, S. V. et al. (2014). Europe PMC Funders Group Dietary intake and body composition in HIV-positive and -negative South African women. Public Helath Nutr. 17:1603-1613.

Wu Leung, W. T. (1968). Food compositi on table for use in Africa. Rome, Italy: FAO

Zeba, N. A., Delisle, H. F. and Renier G. (2014). Dietary patterns and physical inactivity, two contributing factors to the double burden of malnutrition among adults in Burkina Faso, West AFrica. J. Nutr. Sci. 3:1-14.

Zhu, F. et al. (2008). Technology-assisted dietary assessment. Nat Inst. Health. 20:1-16.

Zingoni, C. et al. (2009). Studying a population undergoing nutrition transition: A practical case study of dietary assessment in Urban South African adolescents. Eco. Food Nutr. 48:178-198. 